\title{
Geological mapping of the Ac-10 Rongo Quadrangle of Ceres
} \author{
K.H.G. Hughson' ${ }^{g}$, A. Naßc ${ }^{c}$ D.A. Williams ${ }^{\text {h }}$, F. Preusker ${ }^{c}$ \\ a Max Planck Institute for Solar System Research, Justus-von-Liebig-Weg 3, 37077 Göttingen, Germany \\ b Planetary Science Institute, 1700 E. Fort Lowell Rd., Suite 106, Tucson, AZ 85719-2395, USA \\ ' Institute of Planetary Research, German Aerospace Center (DLR), Rutherfordstr. 2, 12489 Berlin, Germany \\ ${ }^{\mathrm{d}}$ Planetary Sciences and Remote Sensing, Freie Universität Berlin, Malteserstr. 74-100, 12249 Berlin, Germany \\ e Johns Hopkins University Applied Physics Laboratory, Laurel, MD 20723, USA \\ ${ }^{\mathrm{f}}$ NASA Goddard Space Flight Center, Greenbelt, MD 20771, USA \\ ${ }^{g}$ University of California Los Angeles, Los Angeles, CA 90024, USA \\ ${ }^{\mathrm{h}}$ School of Earth and Space Exploration, Arizona State University, Box 871404, Tempe, AZ 85287-1404, USA
}

T. Platz ${ }^{a, b, *}$ A. Nathues ${ }^{a}$, H.G. Sizemore ${ }^{b}$, D.A. Crown ${ }^{b}$, M. Hoffmann ${ }^{a}$, M. Schäfer ${ }^{a, c}$, N. Schmedemann ${ }^{\mathrm{d}}$, T. Kneissl ${ }^{\mathrm{d}}$, A. Neesemann ${ }^{\mathrm{d}}$, S.C. Mest ${ }^{\mathrm{b}}$, D.L. Buczkowski ${ }^{\mathrm{e}}$, O. Ruesch ${ }^{\mathrm{f}}$,

\section{A R T I C L E I N F O}

\section{Article history}

Received 18 January 2017

Revised 19 July 2017

Accepted 1 August 2017

Available online 18 August 2017

\section{Keywords:}

Impact processes

Asteroid Ceres

Asteroid surfaces

Cratering

Image processing

Volcanism

\begin{abstract}
A B S T R A C T
The Dawn spacecraft arrived at dwarf planet Ceres in spring 2015 and imaged its surface from four successively lower polar orbits at ground sampling dimensions between $\sim 1.3 \mathrm{~km} / \mathrm{px}$ and $\sim 35 \mathrm{~m} / \mathrm{px}$. To understand the geological history of Ceres a mapping campaign was initiated to produce a set of 15 quadranglebased geological maps using the highest-resolution Framing Camera imagery. Here we present the geological map of the Ac-10 Rongo Quadrangle, which is located at the equator encompassing the region from $22^{\circ} \mathrm{N}$ to $22^{\circ} \mathrm{S}$ and $288^{\circ}$ to $360^{\circ} \mathrm{E}$. The total relief within the quadrangle is $11.1 \mathrm{~km}$ with altitudes ranging from about $-7.3 \mathrm{~km}$ to $+3.8 \mathrm{~km}$. We identified nine geological units based on surface morphology and surface textural characteristics. The dominant and most widespread unit is the cratered terrain (crt) representing ancient reworked crustal material. Its consistent formation age across the quadrangle is 1.8 Ga. Two edifices (unit th), Ahuna Mons and an unnamed tholus within Begbalel Crater, are interpreted to be of (cryo)volcanic origin. The southwest portion of the quadrangle is dominated by ejecta material (Ye) emplaced during the formation of the $260-\mathrm{km}$ diameter Yalode impact basin at about $580 \mathrm{Ma}$. Rayed crater ejecta material ( $c r$ ) is dominant in the eastern part of the quadrangle but also occurs in isolated patches up to a distance of $455 \mathrm{~km}$ from the $34 \mathrm{~km}$ diameter source crater Haulani. The remaining five geological units also represent impact crater materials: degraded rim (crdeg), bright crater $(c b)$, hummocky floor ( $c f h)$, talus $(t a)$, and crater $(c)$ materials.

Widespread Yalode and Haulani ejecta materials can potentially be utilised as stratigraphic markers. Therefore, it is essential to consistently map their full areal extent and to date their formations using impact crater statistics.
\end{abstract}

(c) 2017 Elsevier Inc. All rights reserved.

\section{Introduction}

The Dawn spacecraft was captured by Ceres' gravity on 6 March 2015. On-board spacecraft instruments include two identical Framing Cameras (FC; Sierks et al., 2011), a Visible and Infrared Mapping Spectrometer (VIR; De Sanctis et al., 2011), and a Gamma Ray and Neutron Detector (GRaND; Prettyman et al., 2011). Between April 2015 and August 2016 the Framing Camera acquired panchromatic (clear filter, F1) and colour (seven fil-

\footnotetext{
* Corresponding author at: Max Planck Institute for Solar System Research, Justus-von-Liebig-Weg 3, 37077 Göttingen, Germany.

E-mail address: platz@mps.mpg.de (T. Platz).
}

ters, F2-F8) images (Sierks et al., 2011) of Ceres' surface from four consecutively lower orbits at various spatial ground resolutions: Rotation Characterisation 3 (RC3; $\sim 1.3 \mathrm{~km} / \mathrm{px}[\sim 6.3 \mathrm{px} / \mathrm{deg}]$ ), Survey Orbit $(\sim 415 \mathrm{~m} / \mathrm{px}[\sim 19.8 \mathrm{px} / \mathrm{deg}])$, High-Altitude Mapping Orbit (HAMO; $\sim 140 \mathrm{~m} / \mathrm{px}[\sim 58.6 \mathrm{px} / \mathrm{deg}]$ ), and Low-Altitude Mapping Orbit (LAMO; $\sim 35 \mathrm{~m} / \mathrm{px}[\sim 234.4 \mathrm{px} / \mathrm{deg}]$ ).

Understanding the geological evolution of dwarf planet Ceres is one of the key objectives of the Dawn mission. A first major step to achieve this goal was the initiation of global and quadrangle-based geological mapping efforts, similar to what has been done at Vesta (Williams et al., 2014; Yingst et al., 2014). The quadrangle scheme (Fig. 1) for the final LAMO-based geological map series is based on the 15-tile HAMO atlas (Roatsch et al., 2016a). Each quadrangle was geologically mapped iteratively on imagery from three mapping 


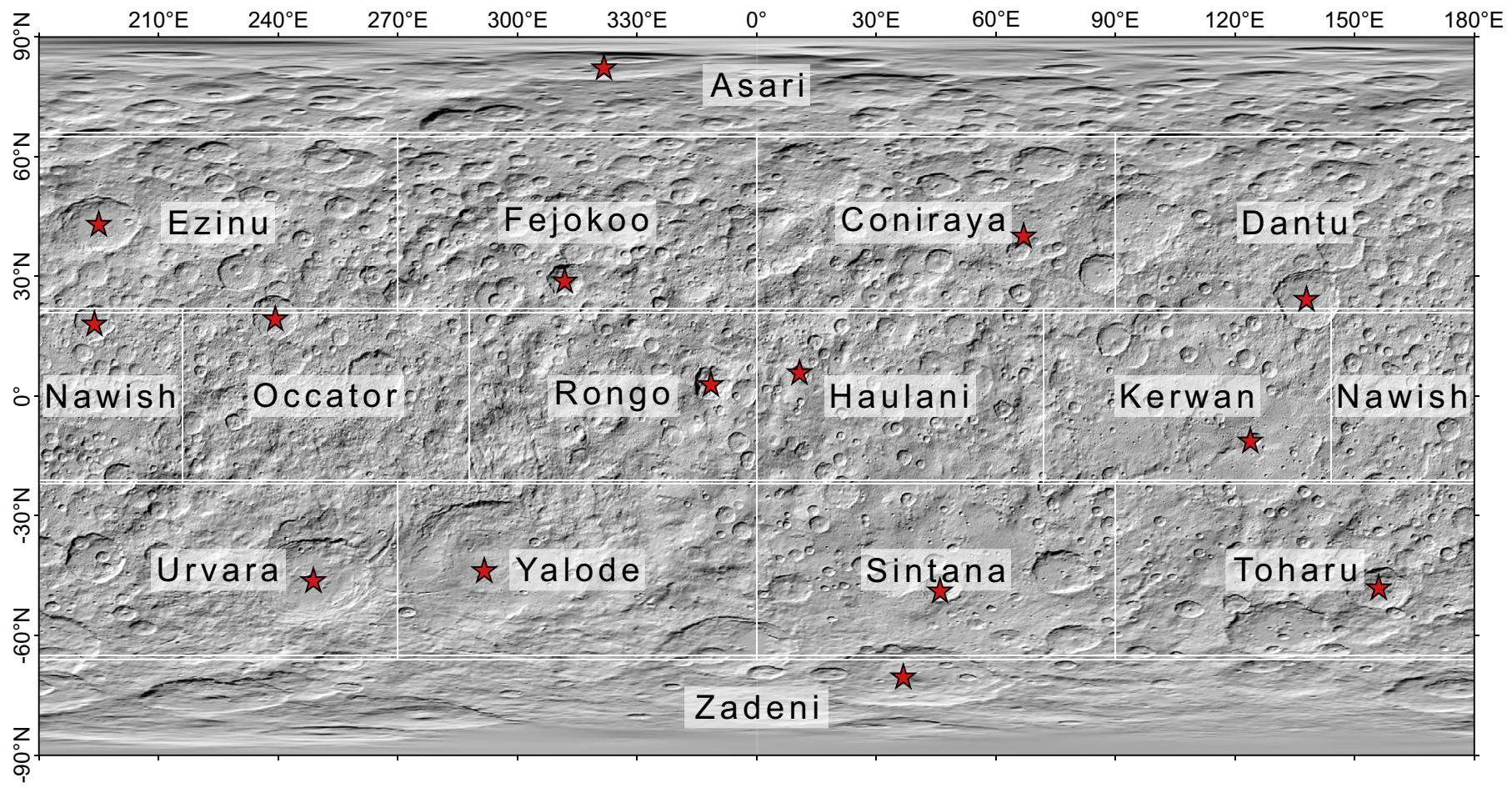

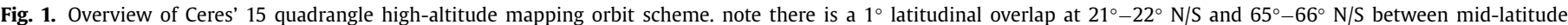

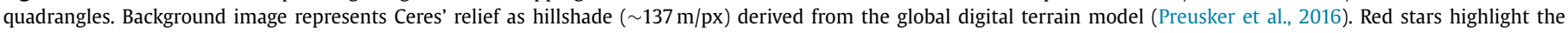
eponymous crater for each quadrangle.

orbits (Survey, HAMO, LAMO) at consecutively higher resolution (e.g., Platz et al., 2015a, 2015b, 2016a). An initial Survey-based global geological map of Ceres is presented in Buczkowski et al. (2016). A HAMO-based global geological map at a scale of 1:2.5 M is currently being produced in parallel (Mest et al., 2017).

The nomenclature for surface features on Ceres-the Roman goddess of agriculture, fertility, and motherly love-is based on international gods and goddesses of agriculture (sensu lato) and agricultural festivals. The $68 \mathrm{~km}$ diameter Rongo Crater $\left(3.21^{\circ} \mathrm{N} / 348.71^{\circ} \mathrm{E}\right)$ is the eponym for the Ac-10 Rongo Quadrangle and is named after Rongo mā Tāne-Māori god of kumara and all cultivated foods. Due to the quadrangle's location at equatorial region it is well illuminated, and therefore, exhibits maximum surface temperatures of $155 \mathrm{~K}$ (Hayne and Aharonson, 2015). The geological map of the Ac-10 Rongo Quadrangle presented in this study introduces and describes nine geological units and discusses the geological evolution of this region.

\section{Methods}

\subsection{Datasets}

Map bases for geological mapping of the Ac-10 Rongo Quadrangle are the LAMO clear filter (panchromatic; 0.4$1.0 \mu \mathrm{m}$ ) nadir mosaic $(30 \mathrm{~m} / \mathrm{px}$ ) (Fig. 2a) and the HAMOderived stereophotogrammetry-based Digital Terrain Model (DTM; 137 m/px; Preusker et al., 2016) (Fig. 2b). Auxiliary datasets include an uncontrolled composite HAMO anaglyph (100 m/px) (Fig. 3), an excerpt of the global HAMO-based RGB map $(R=0.97 \mu \mathrm{m}$, $\mathrm{G}=0.75 \mu \mathrm{m}, \mathrm{B}=0.44 \mu \mathrm{m}, 100 \mathrm{~m} / \mathrm{px}$; Nathues et al., 2016) (Fig. 4), and a photometrically corrected reflectance mosaic obtained at $0.55 \mu \mathrm{m}$ (filter 2) (Annex 2). Statements in this work about different colours occurring on Ceres are based on the RGB map as defined above. All maps utilise IAU-approved nomenclature and the Kait longitude system (Roatsch et al., 2016b). We note that throughout this study the term image resolution is used to refer to image pixel size with units of metres per pixel or pixels per degree, although it relates to pixel scale or ground sampling dimension.

During the early LAMO imaging campaign, the surface of Ceres was first recorded in nadir views (cycles 0-4) and then in off-nadir pointing views (cycles 5-11) (Annex 1). Raw FC clear images (level 1A) were converted to radiometrically corrected images (level 1B) using the MPS in-house software Calliope and parameters reported in Schröder et al. (2013). To create a LAMO-based mosaic, we processed FC images in equirectangular projection on a sphere of radius $470 \mathrm{~km}$, centred at $0^{\circ} \mathrm{N} / 0^{\circ} \mathrm{E}$ with a resolution of $30 \mathrm{~m} / \mathrm{px}$ using the Integrated Software for Imagers and Spectrometers (ISIS; Torson and Becker, 1997). Prior to map-projecting images, a tonematching algorithm was applied to remove high contrasts along image overlaps. The mosaicking order was chosen such that nadir images are located in the foreground and off-nadir images in the background of the mosaic. Only a very few off-nadir images were needed to fill the gaps in the nadir mosaic (Annex 1).

The Rongo composite HAMO anaglyph (Fig. 3) is produced from 60 individual anaglyphs using improved spacecraft pointing and instrument pointing kernels derived from HAMO stereophotogrammetric processing (Preusker et al., 2016). Selection of stereo image pairs was advanced following the criteria reported in Becker et al. (2015). Colour mosaics have been processed according to Nathues et al. (2015) and references therein.

We note that all clear filter images and mosaics are processed as 32-bit images, thus keeping the original 14-bit resolution of the camera. The large dynamical range in digital numbers of 32-bit images compared to standard 8-bit image products reveal more detail, and hence, support geological mapping efforts.

\subsection{Mapping methods}

For the LAMO-based geological mapping campaign (Williams et al., 2017, this issue) a selected and standardised set of symbols for planetary surface features was compiled from the Digital Cartographic Standard for Geologic Map Symbolisation (FGDC, 2006). This 


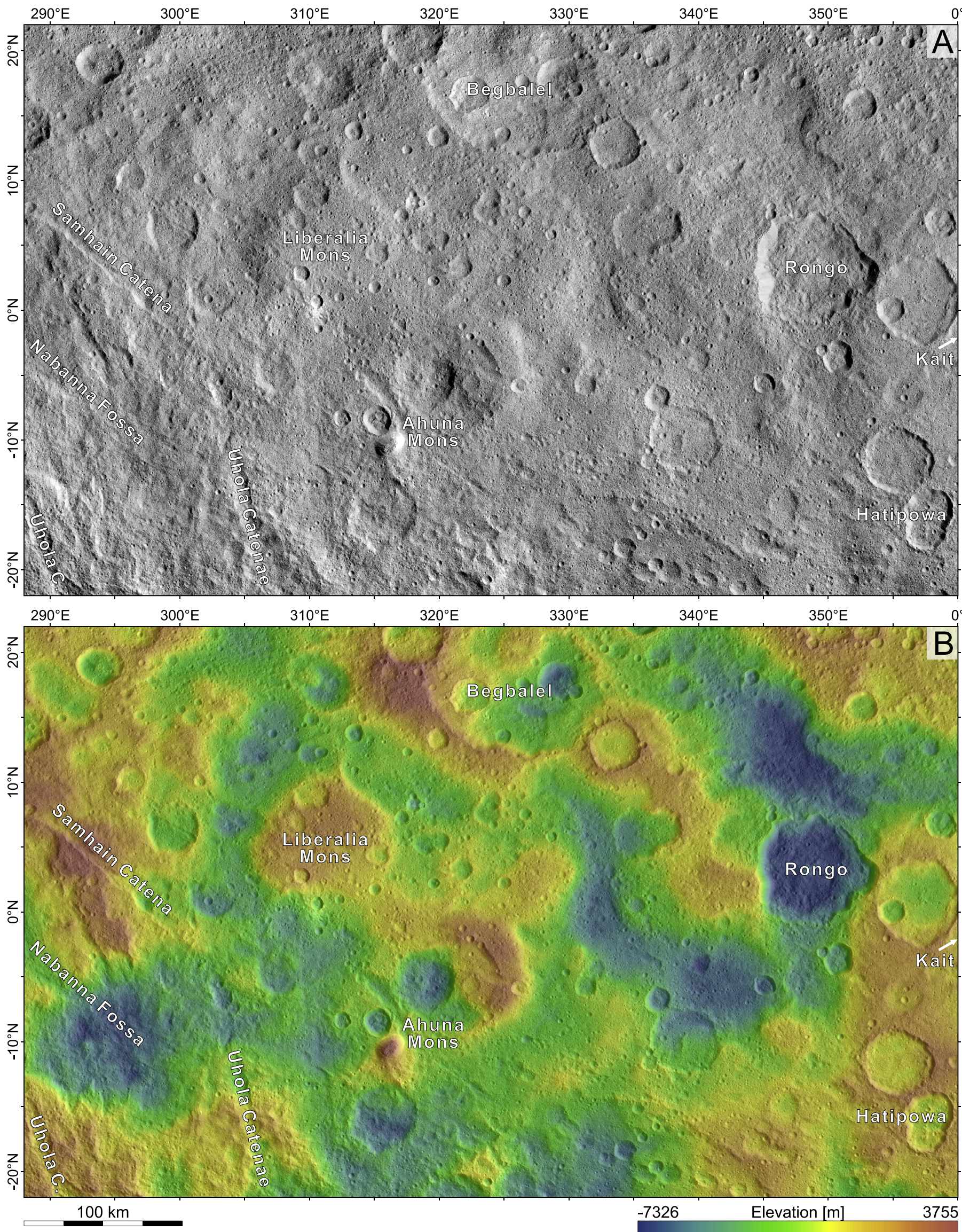

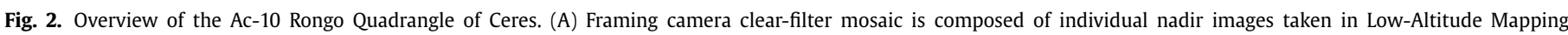

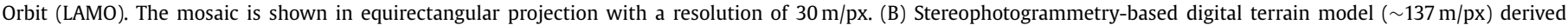
from high-altitude mapping orbit images is superimposed on the LAMO clear-filter mosaic. Same projection as in (A). 


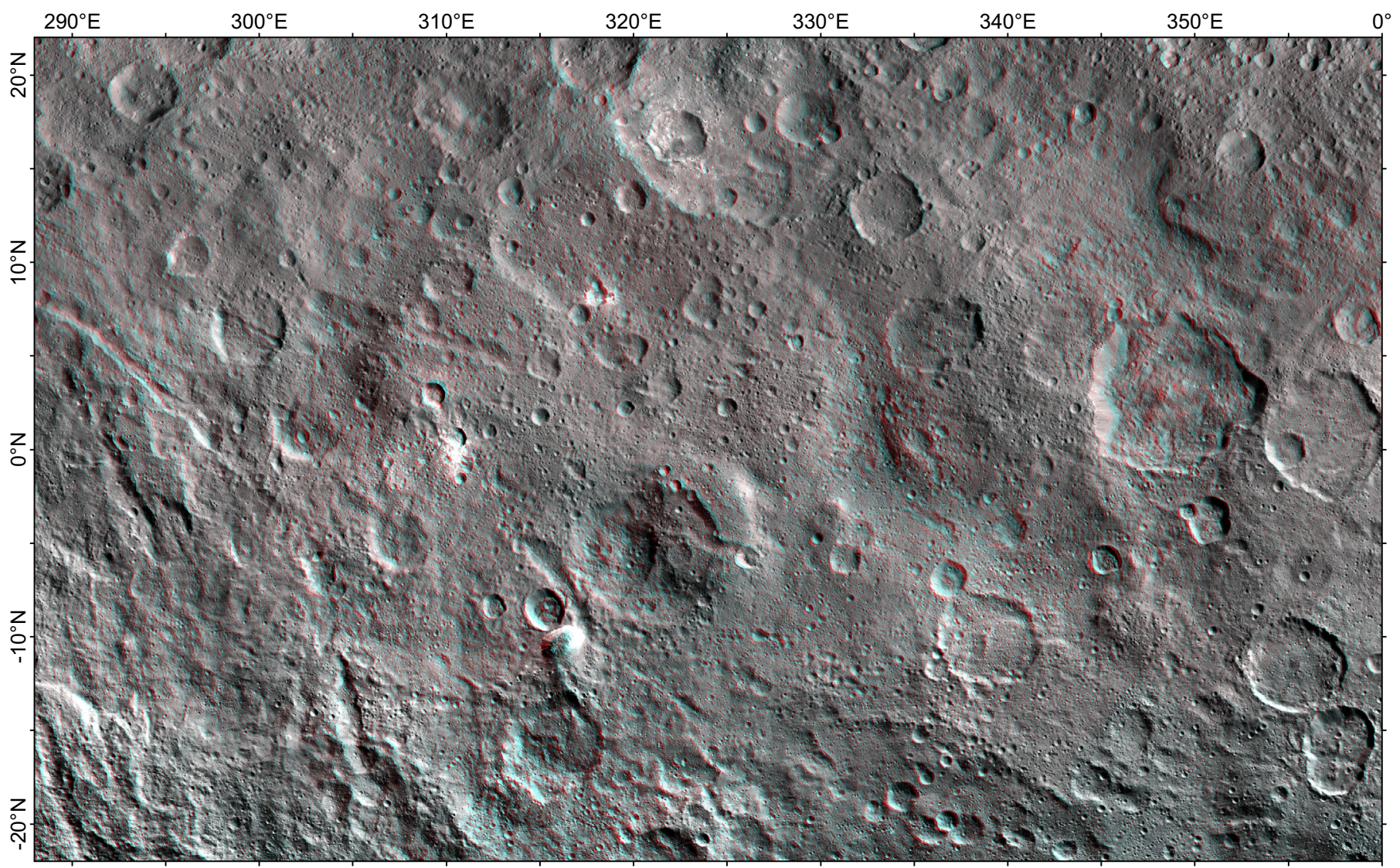

$100 \mathrm{~km}$

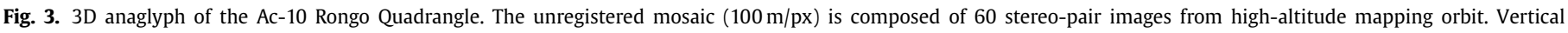
exaggeration varies across individual stereo pairs but is on the order of factors 2 and 3 .

standard was implemented into an ArcGIS geodatabase and then provided by Nass et al. (2011, 2015, 2017) for LAMO-based quadrangle mapping of Ceres. This geodatabase contained the following features: contacts (accurate, approximate, inferred, concealed, and gradational), surface features (e.g., depression, topographic rise), point features (e.g., central peak, small tholus), linear features (e.g., raised rim of large impact crater, fracture, trough), and the 15-tile HAMO quadrangle boundaries according to Roatsch et al. (2016a).

The LAMO-based geological map of the Ac-10 Rongo Quadrangle (Fig. 6) was created in ArcGIS at a map scale of $1: 125 \mathrm{~K}$ to be represented at a print scale of $1: 500 \mathrm{~K}$ (the geological map presented in Annex 3 is shown at a scale of $1: 1 \mathrm{M}$ ). Mapping guidelines regarding, for example, minimum length of and minimum spacing between linear features are listed in Table 2 of Williams et al. (2017, this issue). Only three contact types-certain, approximate and inferred-were utilised during mapping of the Rongo quadrangle. Clear (i.e., certain) contact relationships are often indistinct, especially for more degraded impact craters and associated ejecta materials. A certain contact is only applied in two instances at fresh impact craters exposed on the southern flank of Liberalia Mons where a sharp contact is apparent between crater floor and crater wall materials. The 'inferred' contact type is applied to the Yalode sourced ejecta material. Impact craters rims were mapped as line features for which different symbols were utilised depending on crater size (raised rim of large impact craters for $D \geq 10 \mathrm{~km}$ and raised rim of small impact craters for $5 \leq \mathrm{D}<10 \mathrm{~km}$ ). Craters with diameters less than $5 \mathrm{~km}$ were not mapped to avoid cluttering. In order to apply diameter-dependent symbols, all impact craters in the quadrangle were mapped to $5 \mathrm{~km}$ diameter using the ArcGIS add-in CraterTools (Kneissl et al., 2011). The symbol 'buried impact crater rim' was applied, where applicable, to craters larger than $5 \mathrm{~km}$ in diameter. The 'basin ring' symbol was only used for craters with diameters larger than $200 \mathrm{~km}$. In one instance the lobate scarp signature was applied $\left(12.5^{\circ} \mathrm{N} / 348.2^{\circ} \mathrm{E}\right)$. In contrast to cartographic standards, the hachures here point upscarp since the base of the scarp is much better defined than the top of the scarp.

The Rongo quadrangle exhibits substantial topographic relief. Because it was impossible to adequately represent broad but subtle and partially coalesced topographic rises on the map, main depressions were mapped instead along contour lines. Ahuna Mons and an unnamed tholus were mapped on the basis of contacts or change in slope. Liberalia Mons is a distinct topographic rise but is indistinct from the cratered terrain with respect to surface characteristics; therefore, for its representation on the map, the surface feature symbol 'topographic rise or hill' was applied.

Primary (LAMO clear-filter mosaic and HAMO DTM) and auxiliary (RGB, anaglyph, and reflectance; all HAMO) maps were also viewed in the ISIS image viewer qview to apply customised linear histogram stretches on the full resolution grey scale imagery. It is emphasised that the RGB false-colour mosaic was not used to map lithological units, but it aided identification of Haulanisourced crater rays. Crater rays were only mapped if visible in the LAMO clear-filter mosaic. A stippled pattern was applied to indicate the broader extent of thin Haulani-sourced ejecta material appearing in white-to-bluish colours. Note that some mapped craterray polygons are too narrow for an acceptable representation on the map at print scale. However, in this case the accurate documentation of the Haulani Crater rays and their potential for being a regional stratigraphic marker outweighed map readability. 


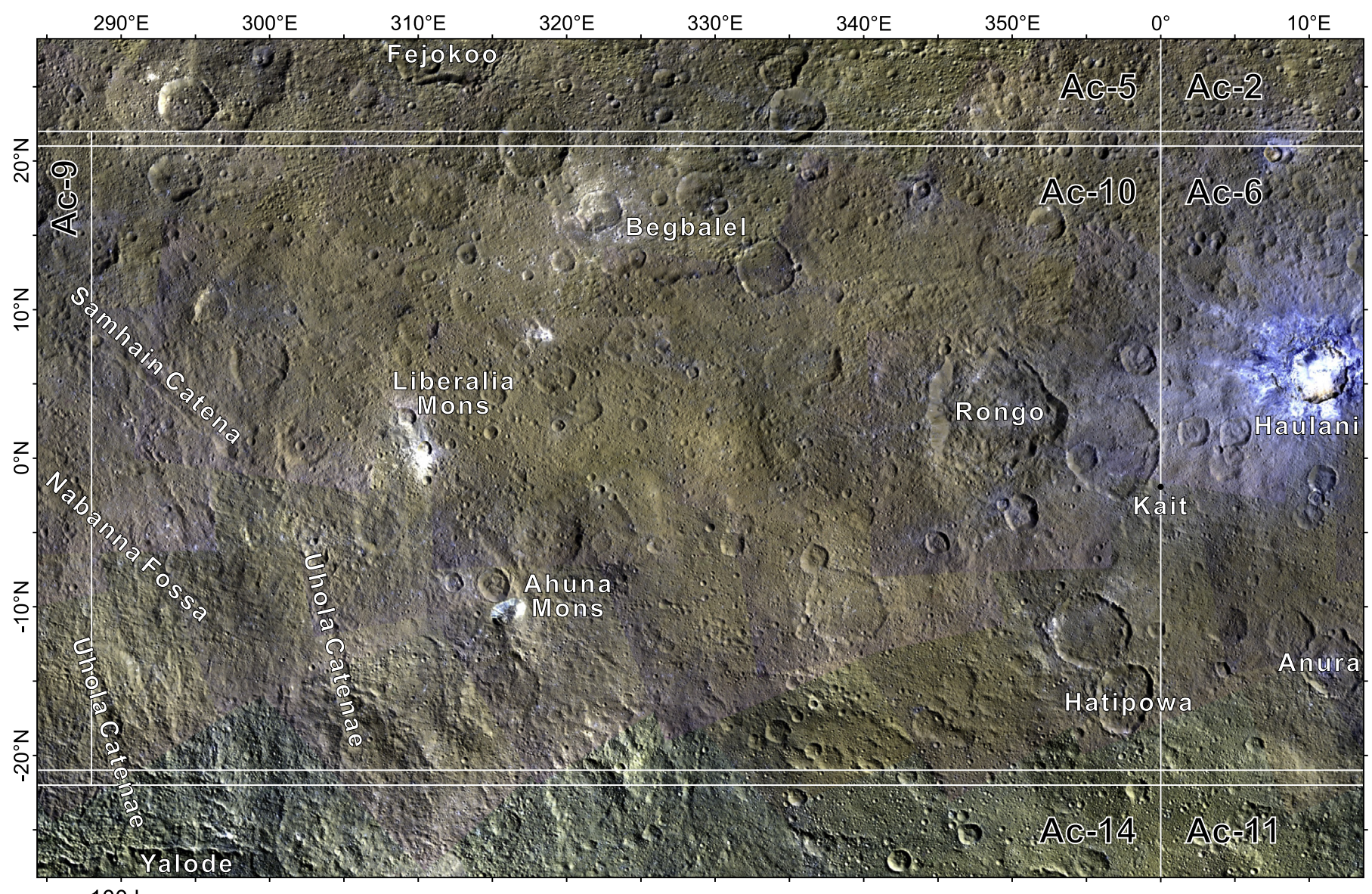

$100 \mathrm{~km}$

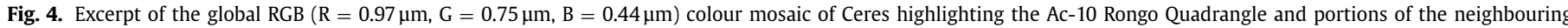

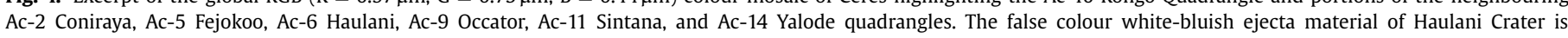

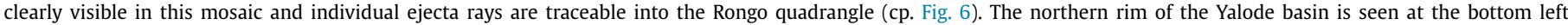
of the scene. (For interpretation of the references to colour in this figure legend, the reader is referred to the web version of this article.)

\subsection{Crater size-frequency distribution analysis}

For crater-based age dating impact craters with diameters $\geq 800 \mathrm{~m}$ were mapped as circular-symmetric polygons using the ArcGIS add-in CraterTools (Kneissl et al., 2011). Note these polygons can appear elliptical or oval depending on data projection, but crater diameters are calculated independent of applied projection (Kneissl et al., 2011). For all craters intersecting the counting area, crater centre coordinates and diameters as well as counting area vertices and area size, were exported to a spatial crater count (scc) text file for crater size-frequency distribution (CSFD) analysis in the IDL-based software Craterstats (Michael and Neukum, 2010). Each crater count of a representative area of a single geological unit was tested for randomness using the two methods described in Michael et al. (2012) and implemented in Craterstats-the mean second closest neighbour distance and the standard deviation of adjacent areas. In case clustering is indicated in a particular root2 crater diameter bin, this area is inspected and, if applicable, excluded from the crater count (i.e., the secondary crater cluster and its enveloping area are excluded). In the final step absolute model ages are calculated using the lunar-derived production and chronology functions of Hiesinger et al. (2016) and the Poisson timing analysis by Michael et al. (2016).

For Ceres two approaches exist to obtain absolute model ages from derived production and chronology functions: the lunarderived model and the asteroid-derived model (Hiesinger et al., 2016). While the lunar-derived model adapts the well-known lunar chronology and production functions scaled to Ceres' conditions (e.g., surface gravity, impact velocity, target material strength), the asteroid-derived model utilises scaling of the observed size-frequency distribution of main-belt objects (cf. Hiesinger et al., 2016). In this study only the lunar-derived model functions are discussed because the measured crater size-frequency distributions exposed on single geological units are best represented by the lunar-derived production function. However, measured crater size-frequency distributions and derived model ages are documented for both models (Annexes 7 and 8 ).

An at-a-glance visualisation of the spatial distribution of impact craters is found by utilising kernel density maps. An ArcGIS routine was used to produce such a map based on the craters' centre points. To create Fig. $5 \mathrm{~b}$ all craters $(\mathrm{D} \geq 1.7 \mathrm{~km})$ intersecting the quadrangle boundaries are used and the point density per square kilometre was calculated using the geodetic distance values and the default radius option for neighbourhood analysis.

\section{Regional geology}

\subsection{Physiographic setting}

The equatorial Ac-10 Rongo Quadrangle is defined as the region $22^{\circ} \mathrm{N}-22^{\circ} \mathrm{S}$ and $288^{\circ}-360^{\circ} \mathrm{E}$ covering an area of $207,817 \mathrm{~km}^{2}$ (Fig. 1). It is bordered to the west and east by the quadrangles Ac-9 Occator (Buczkowski et al., 2017, this issue) and Ac-6 Haulani (Krohn et al., 2017, this issue), respectively. Mid-latitudinal quadrangles Ac-5 Fejokoo (Hughson et al., 2017, this issue) and 


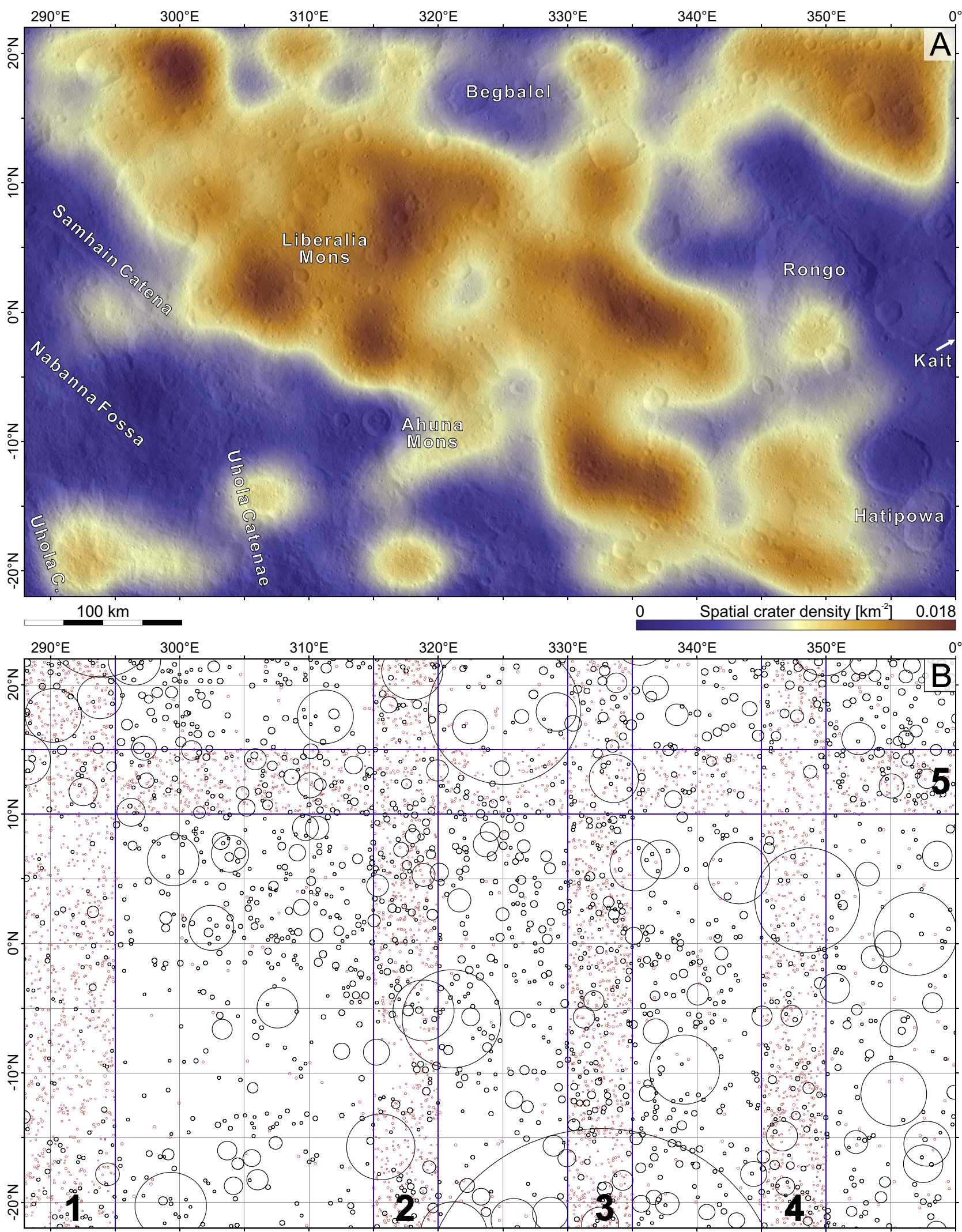

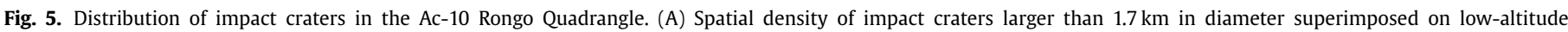

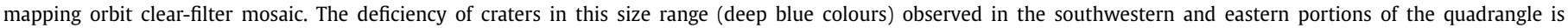

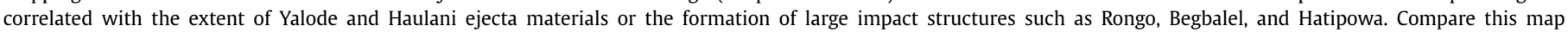

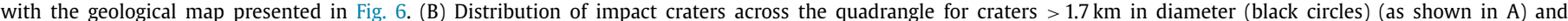

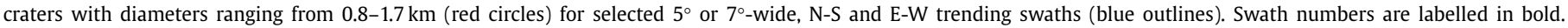
(For interpretation of the references to colour in this figure legend, the reader is referred to the web version of this article.) 


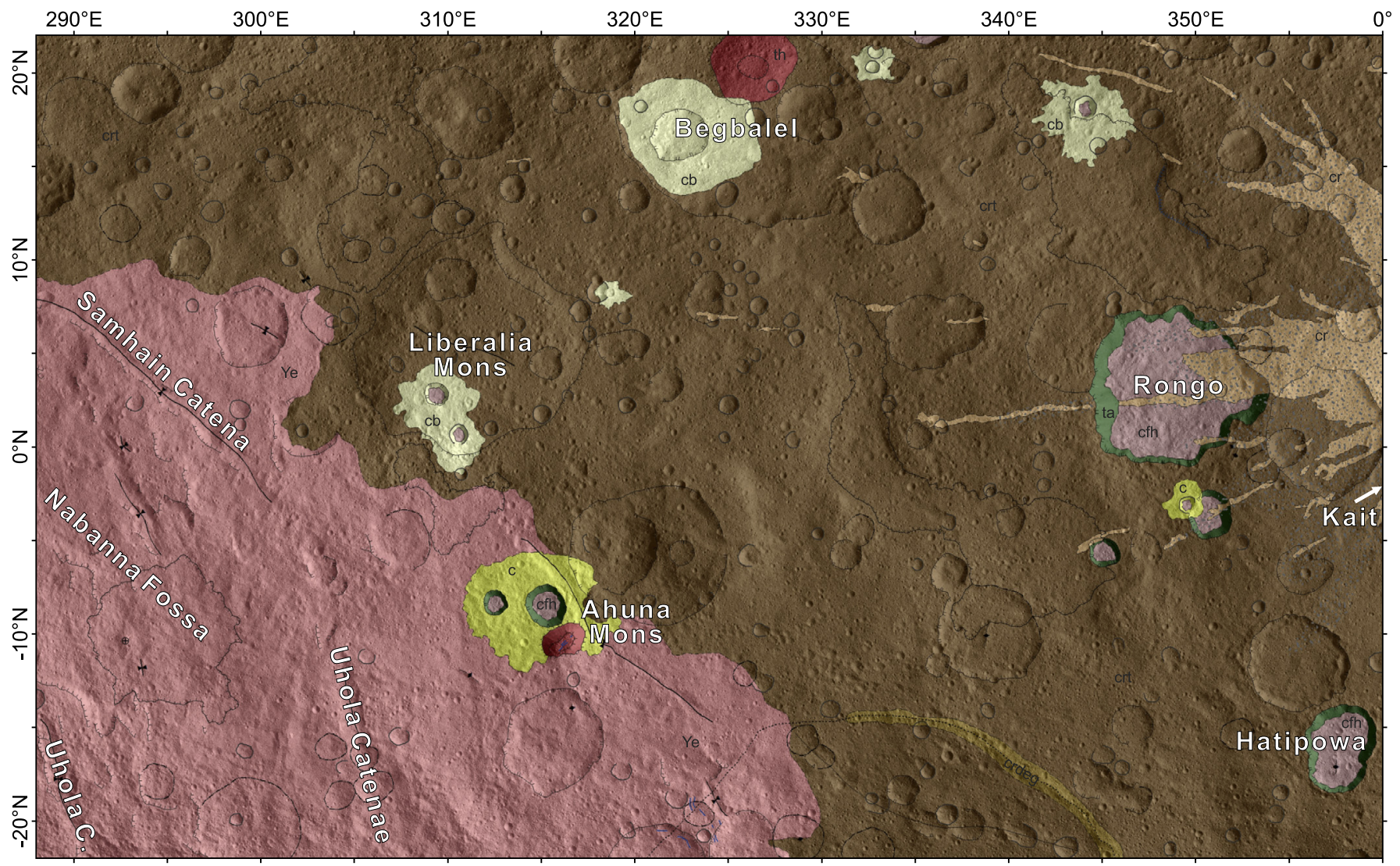

$100 \mathrm{~km}$

\section{GEOLOGICAL UNITS}

\begin{tabular}{|c|c|}
\hline $\mathrm{cb}$ & crater material bright \\
\hline c & crater material \\
\hline $\mathrm{cfh}$ & crater floor material hummocky \\
\hline $\mathrm{cr}$ & crater ray material \\
\hline crdeg & crater rim material degraded \\
\hline ta & talus material \\
\hline $\mathrm{crt}$ & cratered terrain \\
\hline th & tholus material \\
\hline Ye & Yalode ejecta material \\
\hline
\end{tabular}

LINEAR FEATURES

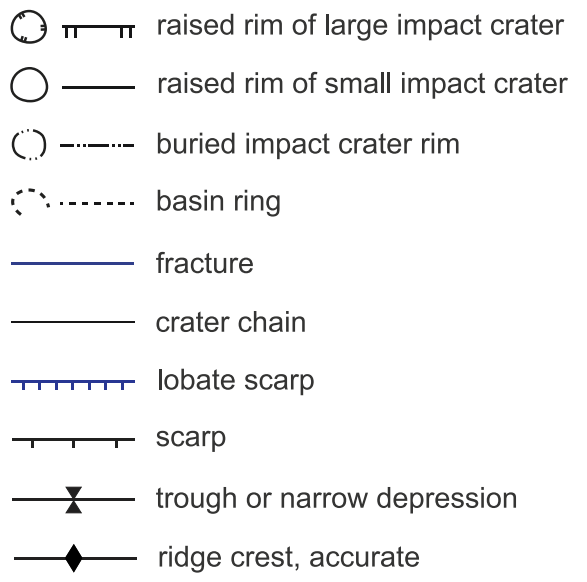

GEOLOGICAL CONTACTS

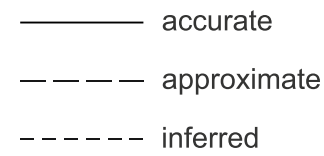

POINT FEATURE

$\oplus \quad$ small tholi (not mapped to scale)

\section{SURFACE FEATURES}

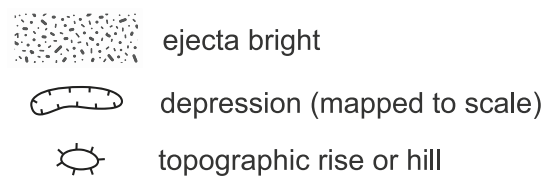

Fig. 6. Geological map of the Ac-10 Rongo Quadrangle of Ceres. High-resolution map sheet is presented in Annex 3.

Ac-14 Yalode (Crown et al., 2017, this issue) border the Ac-10 Rongo Quadrangle to the north and south, respectively. The quadrangle takes its name from Rongo Crater $\left(3.21^{\circ} \mathrm{N} / 348.71^{\circ} \mathrm{E}\right)$, a complex, $68 \mathrm{~km}$ diameter crater located between two subtle topographic rises to its east and west (Figs. 2 and 8). The total topographic relief across the Ac-10 Rongo Quadrangle is $11.1 \mathrm{~km}$ (Fig. 2). The lowest point at $-7326 \mathrm{~m}$ (altitude measured relative to the bestfit triaxial ellipsoid $482 \mathrm{~km} \times 482 \mathrm{~km} \times 446 \mathrm{~km}$ ) is located within Rongo Crater at $4.9^{\circ} \mathrm{N} / 349.1^{\circ} \mathrm{E}$ (Figs. 2 and $8 \mathrm{a}$ ). The low point within Rongo Crater is also the lowest site on Ceres (Nathues et al., 2017). Outside Rongo Crater, the lowest elevation is found in a depression north of Rongo $\left(-7009 \mathrm{~m} ; 13.2^{\circ} \mathrm{N} / 346.6^{\circ} \mathrm{E}\right)$. The high- est regions are found on a plateau, which is dissected by Samhain Catenae, the summit of Ahuna Mons, and portions of the western crater rim of Begbalel. The latter claims the highest elevation of $3755 \mathrm{~m}\left(19.1^{\circ} \mathrm{N} / 315.8^{\circ} \mathrm{E}\right)$. The degraded Begbalel Crater, centred at $17.71^{\circ} \mathrm{N} / 325.35^{\circ} \mathrm{E}$ and $102 \mathrm{~km}$ in diameter, is the largest preserved impact crater within the quadrangle (Fig. 2). Begbalel harbours a number of craters up to $24 \mathrm{~km}$ in diameter on its floor. It also accommodates a $34 \mathrm{~km}$ diameter, near-circular plan-view edifice with an elliptical, approximately $1 \mathrm{~km}$ deep summit depression. This depression is breached towards the southeast. The summit altitude relative to the immediate surroundings is approximately $3200 \mathrm{~m}$. 


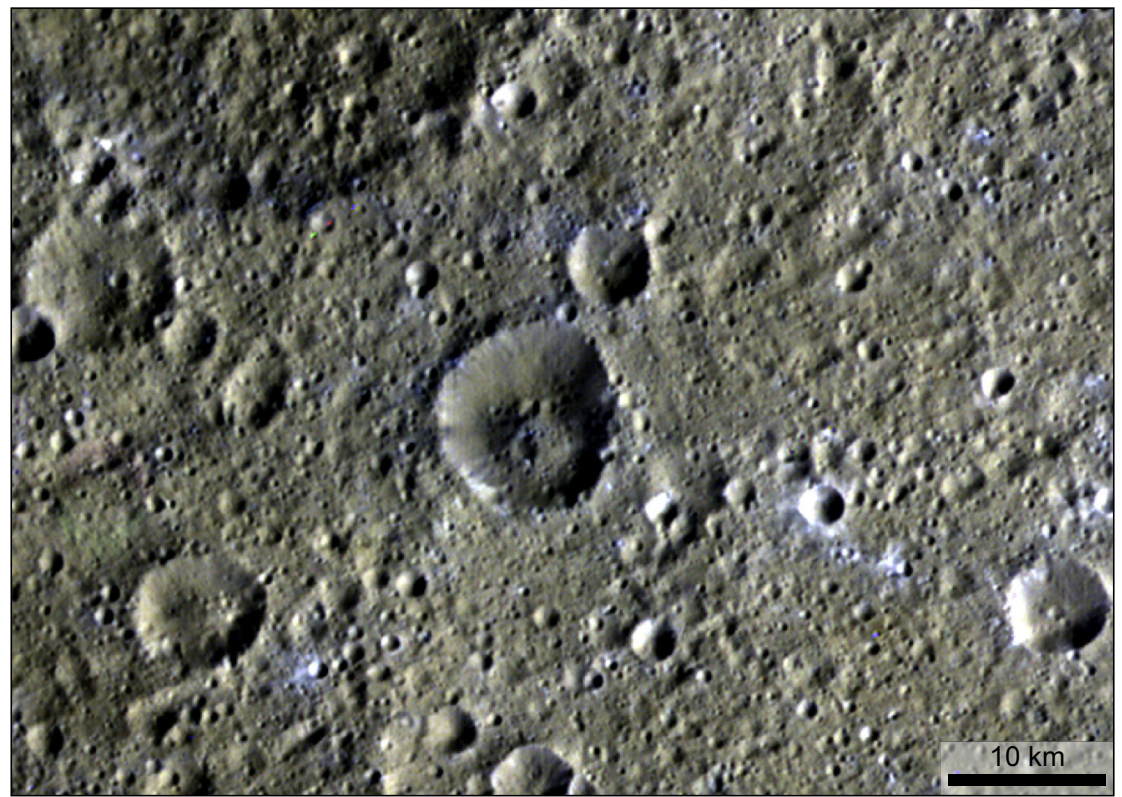

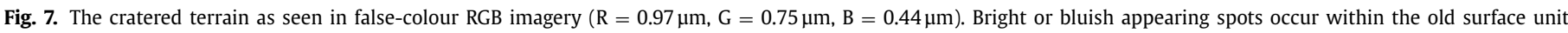

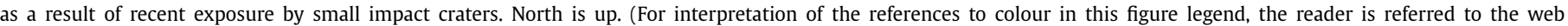
version of this article.)

The $28.4 \mathrm{~km}$ diameter Hatipowa Crater $\left(-15.4^{\circ} \mathrm{N} / 357.8^{\circ} \mathrm{E}\right)$ is located in the southeastern portion of the quadrangle. It is a complex crater whose southern rim is obliterated by an unnamed $23.9 \mathrm{~km}$ diameter crater. Approximately $97 \mathrm{~km}$ to the NNE, the small $0.4 \mathrm{~km}$ diameter crater Kait $\left(-2.1^{\circ} \mathrm{N} / 0^{\circ} \mathrm{E}\right)$ defines the prime meridian of Ceres (Roatsch et al., 2016b).

Liberalia Mons, centred at $6.02^{\circ} \mathrm{N} / 311.01^{\circ} \mathrm{E}$, measures $\sim 90 \mathrm{~km}$ across and rises to $\sim 4.5 \mathrm{~km}$ above its surrounding terrain (Fig. 2). Ahuna $\left(-10.5^{\circ} \mathrm{N} / 316.2^{\circ} \mathrm{E}\right)$ Mons, a cryovolcanic edifice (Ruesch et al., 2016), towers up to $5 \mathrm{~km}$ above its surroundings and is located adjacent to a $16.5 \mathrm{~km}$ diameter crater (Fig. 9). Note that the differential altitude between the summit of Ahuna Mons $(3625 \mathrm{~m})$ and the crater floor is $7583 \mathrm{~m}$. Ahuna Mons has roughly an elliptical plan-view outline, approximately $19.4 \mathrm{~km} \times 13.8 \mathrm{~km}$ and is located to its south on a topographic rise that reaches to an altitude of $\sim 1400 \mathrm{~m}$ below its summit. The steep $\left(\sim 30-40^{\circ}\right)$ flanks of Ahuna Mons are composed of a bright (high albedo) material that has been proposed to consist of salts (Ruesch et al., 2016). Recently, Zambon et al. (2017) concluded that the edifice exhibits high abundances of carbonates and low portions of hydrous minerals relative to the average surface composition of Ceres. The appearance and composition of Ahuna Mons make it Ceres' most unique landform and, along with Occator's bright spots, among the most interesting of Dawn's discoveries.

The southwestern portion of the Rongo quadrangle is marked by isolated high-standing terrain dissected by troughs (e.g., Uhola and Samhain Catenae; Fig. 2). The quadrangle's southern border region also hosts a large (200-km diameter) heavily degraded impact basin (Fig. 6).

\subsection{Description of map units}

Geological units prevalent within the Ac-10 Rongo Quadrangle include the widespread unit cratered terrain (crt), tholus material (th), and impact crater-related materials including crater material $(c)$, crater material bright $(c b)$, crater ray material $(c r)$, crater floor material hummocky ( $c f h)$, talus material (ta; i.e., crater walls), crater rim material degraded (crdeg), and Yalode ejecta material (Ye). Contacts have been mapped as 'certain' or 'approximate' for all units except for Yalode ejecta material, where an 'inferred' con- tact was used. Structural features observed in the quadrangle were mapped as fracture, scarp, lobate scarp, trough or ridge crest. To reflect the topographic terrain, depressions and topographic rises were mapped where appropriate using surface feature symbols 'depression (mapped to scale)' and 'topographic rise or hill' (Fig. 6). A stipple pattern (ejecta bright) was applied to visualise the potential extent of Haulani ejecta material as observed in false coloursthe only 'map-by-colour-feature' (Fig. 4).

\subsubsection{Cratered terrain (crt)}

Cratered terrain $(\mathrm{crt})$ is the most widespread unit across the surface of Ceres, and it is characterised by the highest, though variable, impact-crater densities (Buczkowski et al., 2016; Hiesinger et al., 2016; Mest et al., 2017). Within the Ac-10 Rongo Quadrangle the cratered terrain exhibits a rather homogenous crater density. Crater-based age dating suggests an absolute model age of approximately $1.8 \mathrm{Ga}$ for this unit (Annex 7; see section Crater-based model ages). In false RGB colours as shown in Figs. 4 and 7, the cratered terrain appears brownish; it exhibits low absolute reflectances between 0.025 and 0.035 at $0.55 \mu \mathrm{m}$ (Nathues et al., 2016). The standard site for brownish coloured units on Ceres is defined within the Rongo quadrangle, approximately $210 \mathrm{~km}$ east of Ahuna Mons (Nathues et al., 2016). The surface texture is moderately rugged and moderately cratered. Small zones of smoother texture may occur as a function of variability in the size-frequency distribution of small diameter impact craters. Craters $(D \geq 5 \mathrm{~km})$ associated with the cratered terrain exhibit morphologies from slightly degraded (i.e., only a few craters are superimposed and the rim is well defined) to heavily degraded (i.e., major modification of crater rim and floor materials with ejecta material not being identifiable). Note that all impact crater materials mapped as separate units (except Yalode ejecta material and the two craters adjacent to Ahuna Mons) are part of the cratering history of the cratered terrain unit. Numerous exposures of small-scale white-to-bluish coloured materials are observed across the unit. The materials are exposed by small impact craters at various locations (e.g., upper crater rims, crater floors, ejecta materials).

Interpretation: The cratered terrain (ct) appears to be ancient crustal material reworked through impact gardening. The near- 


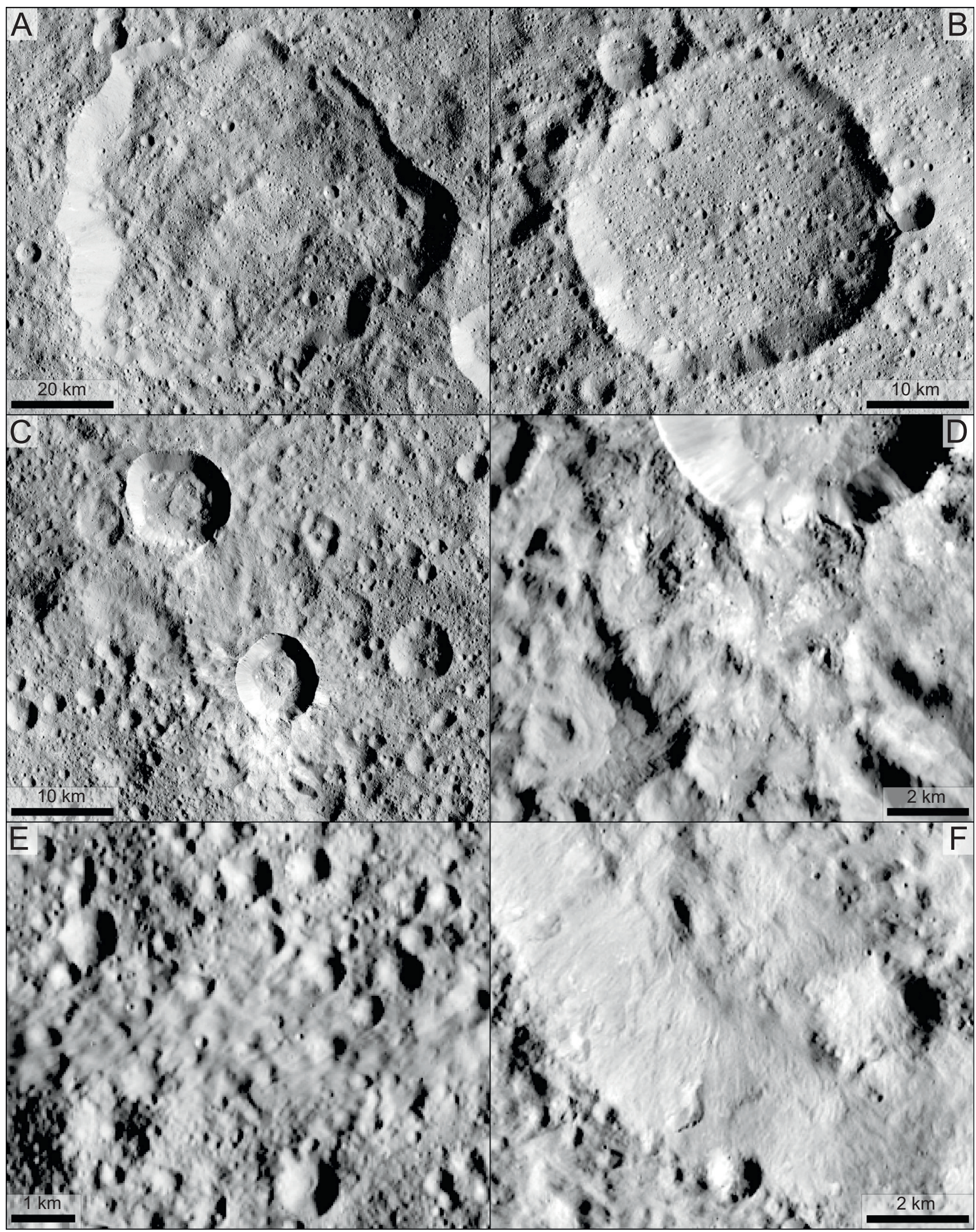

Fig. 8. Selected features present in the Rongo quadrangle. (A) Rongo Crater with a scalloped rim and hummocky-textured floor deposits. (B) Unnamed crater with polygonal outline. This $30.5 \mathrm{~km}$ diameter crater is superimposed on the southeastern rim of Begbalel Crater. (C) Two craters excavated bright material on top of Liberalia Mons. (D) Close-up of the smaller crater portrayed in (C). Narrow fluidised ejecta flow deposits are observed downslope of this $8 \mathrm{~km}$ diameter crater (enhanced FC image 53,309). (E) Haulani-sourced crater ray deposits centred at $2.1^{\circ} \mathrm{N} / 342.2^{\circ} \mathrm{E}$ (approx. $220 \mathrm{~km}$ from source). (F) When Haulani ejecta is emplaced on steep slopes (i.e., crater walls), it can mobilise forming slim and thin flow deposits. Image is centred at $6.1^{\circ} \mathrm{N} / 358.2^{\circ} \mathrm{E}$, approx. $87 \mathrm{~km}$ from source (enhance FC image 65,568 ). North is up in all images. Scenes shown are excerpt of the low-altitude mapping orbit mosaic unless otherwise noted. 


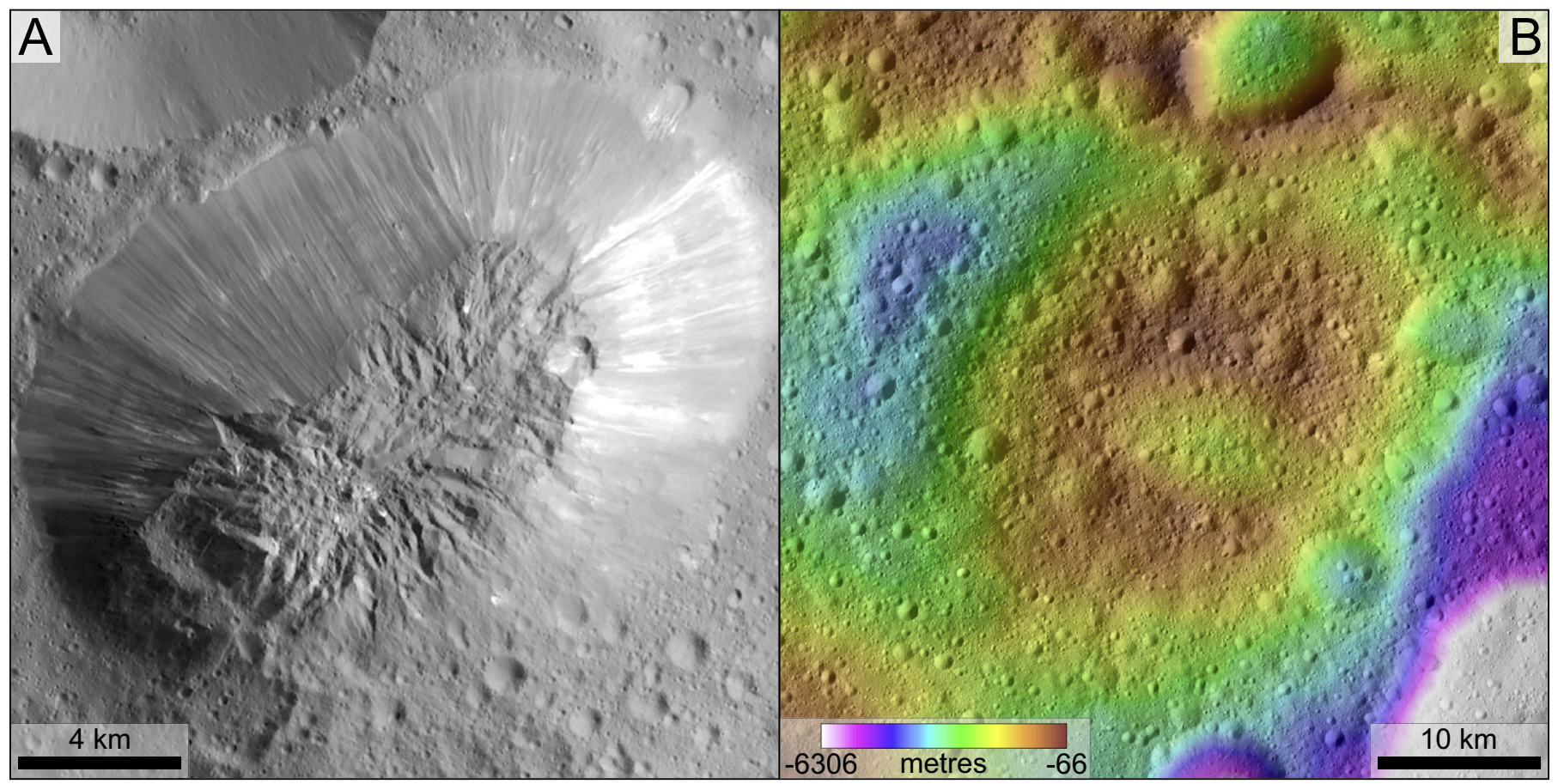

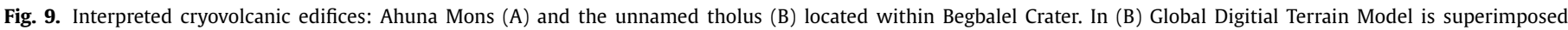
on low-altitude mapping orbit clear filter mosaic.
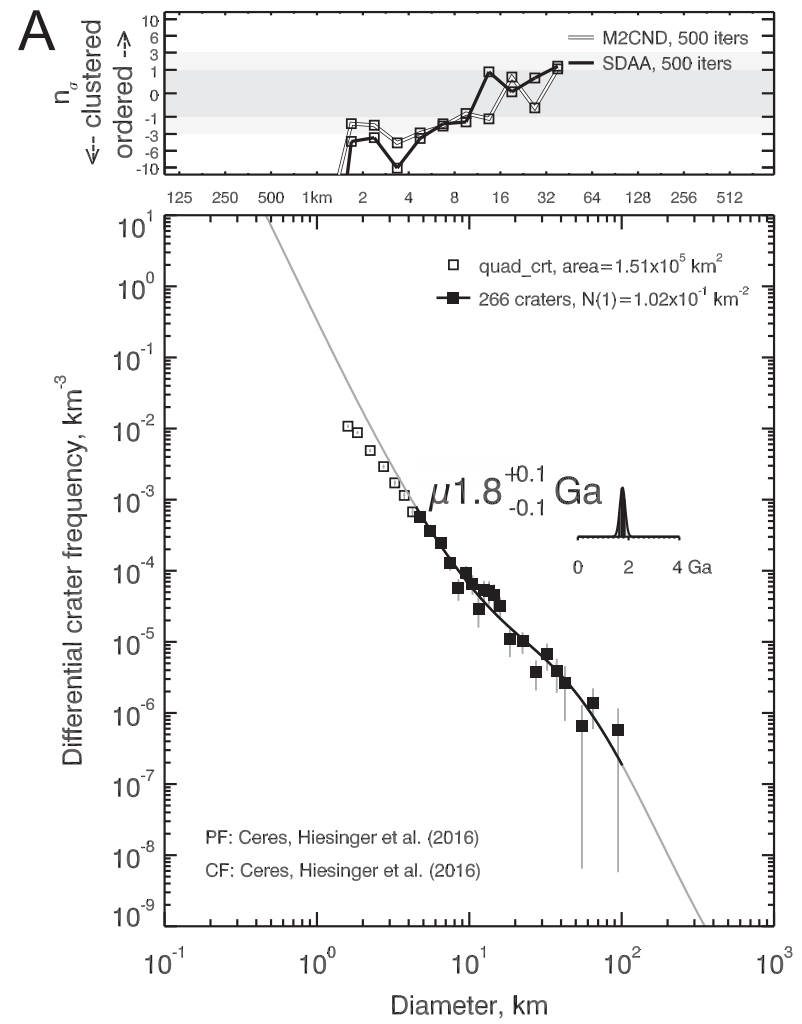
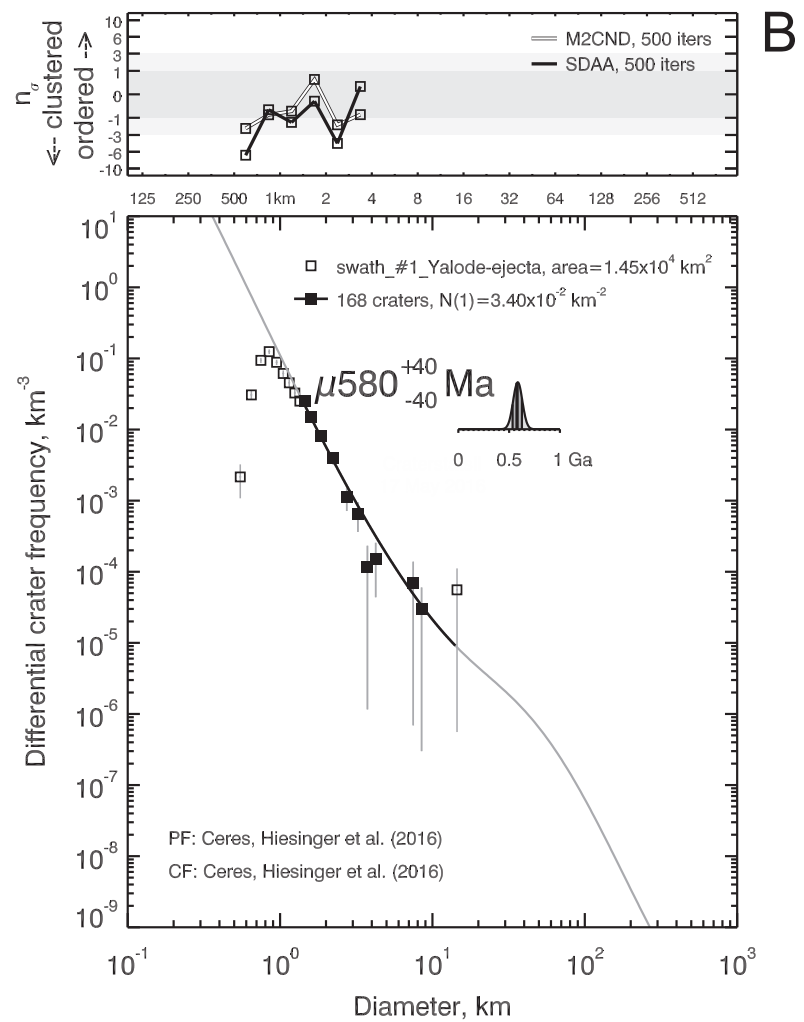

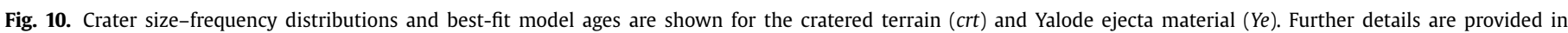
Annexes 6 and 7.

subsurface contains white to bluish coloured material as exposed by small impact craters.

\subsubsection{Tholus material (th)}

Ahuna Mons $\left(-10.5^{\circ} \mathrm{N} / 316.2^{\circ} \mathrm{E}\right)$ and the unnamed tholus $\left(20.3^{\circ} \mathrm{N} / 326.3^{\circ} \mathrm{E}\right)$ within Begbalel Crater are distinct topographic rises (Fig. 9). Ahuna Mons is composed of bright, unconsoli- dated talus material with reflectances up to 0.066 at $0.55 \mu \mathrm{m}$. Reflectances as low as 0.025 belong to darker material and potentially resemble ejecta material (see below). The talus is characterised by small-scale, downslope oriented grooves and occasional large-scale boulders or (consolidated/competent) outcrops. A V-shaped erosional feature along the NW margin of the dome's summit region appears to be connected to a dark streak. This provides direct evi- 


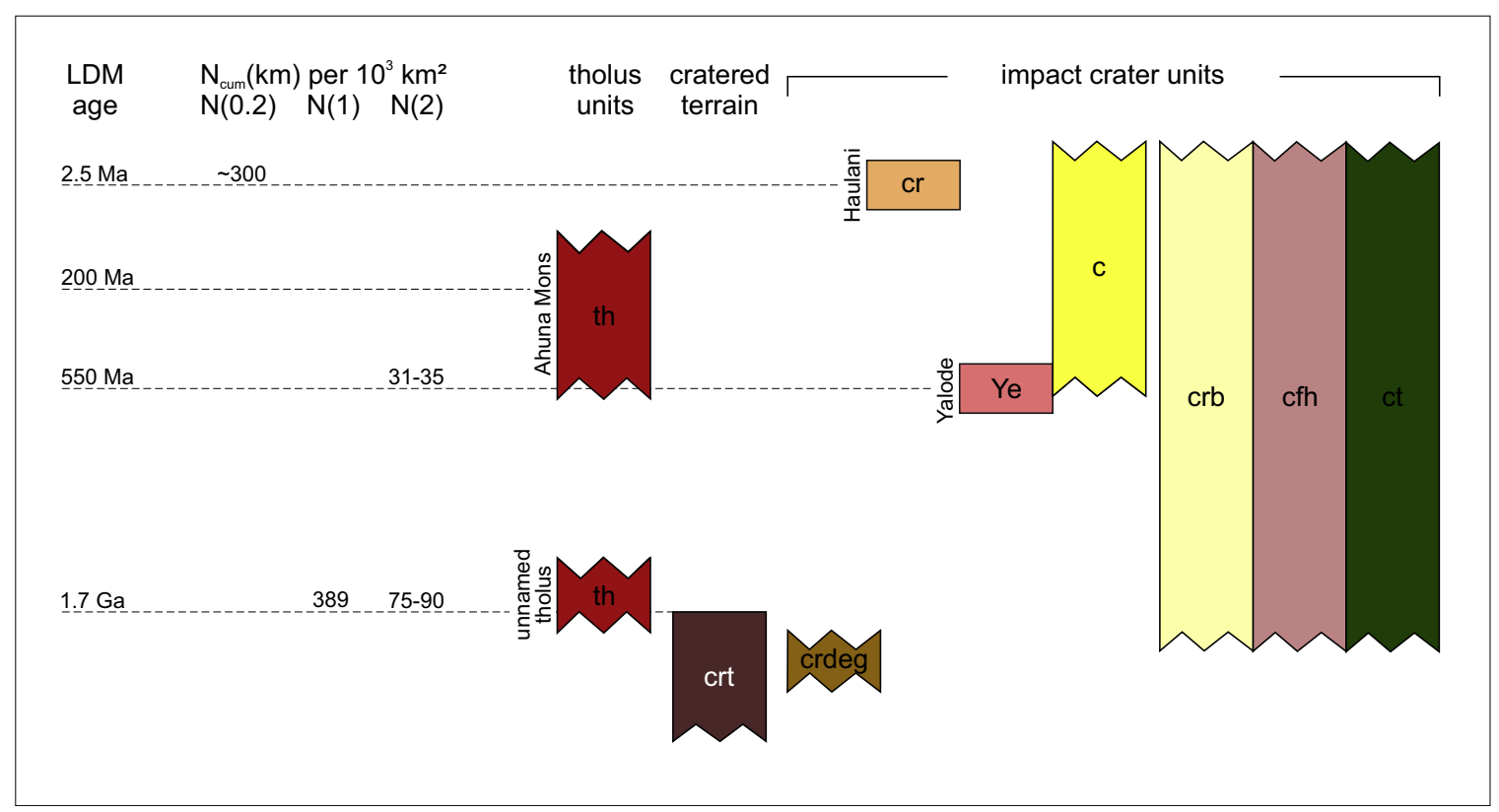

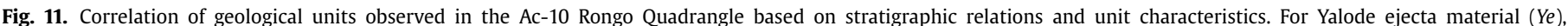

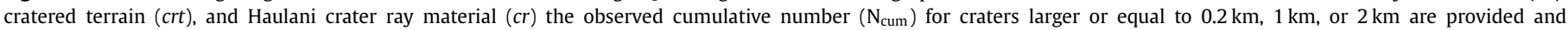

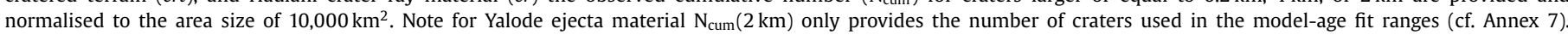

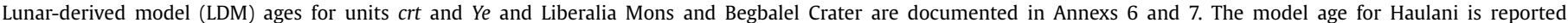

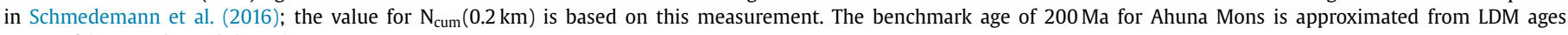
reported in Ruesch et al. (2016).

dence that the talus is from mass-wasting of these summit materials (Fig. 9). There is a sharp, and in some places gradational, contact between flank material and surrounding terrain (Ruesch et al., 2016). A small debris avalanche deposit is noted at the base of the NE flank partially burying a small, approximately $0.7-\mathrm{km}$ diameter crater. The extensively fractured summit region exhibits an elongated central depression with a similar orientation as the edifice. Similar rugged and highly fractured upper surfaces are also known from terrestrial (silicic) viscous domes (Huppert et al., 1982; Platz et al., 2012; Pallister et al., 2013). The summit material has a similar reflectance to the cratered terrain $(\sim 0.03$ at $0.55 \mu \mathrm{m})$. The shallower $\left(\mathrm{c} .20-25^{\circ}\right)$ southern flank of Ahuna Mons is attached to a topographic rise and does not exhibit bright flank material. A peculiar feature is observed at the lower NW flank. Here, the surrounding regolith appears to be arched upwards (Annex 5). This morphology may have formed by downslope movement of ejecta material from the crater immediately to the NW, which was initially deposited onto the steep northern flanks (i.e., the prevalent slope exceeds the angle of repose). During the formation of this $16.5 \mathrm{~km}$ diameter crater, portions of ejecta material may have also been emplaced onto the summit potentially mantling bright summit material. An alternative and more likely scenario for the upward arching of the regolith is that the uplift occurred as a result of edifice expansion due to intrusion of cryomagmatic material. The absence of upwards arched material at the lower eastern flank suggests edifice growth towards the northeast-to-east by the continuous and progressive production of talus material.

The general fresh appearance of Ahuna Mons, crater-based model ages of approx. 160-210 Ma estimated for the surrounding terrain, and the $16.5 \mathrm{~km}$ crater adjacent to the north (Ruesch et al., 2016) all suggest that the initial building phase of the cryovolcanic edifice had been completed around $200 \mathrm{Ma}$, and that latestage eruptive phases occurred subsequently with preferential edifice growth towards the northeast.

The unnamed tholus located in Begbalel Crater has a nearcircular basal outline and is heavily cratered. It is distinct from Liberalia Mons as it does contain an elliptical, $12 \mathrm{~km} \times 10 \mathrm{~km}$, summit depression oriented NW-SE. Its depth is approximately $1-1.1 \mathrm{~km}$ and it is breached towards the SE. Although no bright material is associated with this edifice-possibly the result of continuous impact gardening and subsequent space weathering-its morphology suggests a (cryo)volcanic origin. An analysis of the superimposed crater size-frequency distribution is not straightforward and may hint at a differential resurfacing history similar to what would be expected for an edifice built over an extended period of time. The maximum formation age of the tholus is the formation age of Begbalel Crater, which is estimated to be about $1.9 \mathrm{Ga}$ based on the CSFD of superimposed crater (Annex 7).

Interpretation: The tholus material-Ahuna Mons and the unnamed tholus located in Begbalel Crater-is interpreted to result from emplacement of cryovolcanic edifices based on its morphology and/or surface characteristics.

\subsubsection{Yalode ejecta material (Ye)}

The SW part of the quadrangle differs in surface morphology and texture from the cratered terrain (Fig. 6). The terrain here is more rugged than the cratered terrain and its rather undulating topography. It exhibits a number of trough-like features (Samhain and Uhola Catenae) and well-preserved scarps. The western portions of Uhola Catenae and the Samhain Catenae present in the Ac-9 Occator Quadrangle are oriented radial to the Yalode basin. The distinctive texture of this region covers a large depression and a small tholus in the depression interior $\left(-10.3^{\circ} \mathrm{N} / 292.8^{\circ} \mathrm{E}\right)$. The inferred contact of unit Ye is informed by changes in impact crater densities, in particular the presence of partially buried craters (e.g., the unnamed $32 \mathrm{~km}$ crater located at $6.4^{\circ} \mathrm{N} / 299.5^{\circ} \mathrm{E}$ and the large crater immediately south of Ahuna Mons). At map scale, the surface texture at the immediate vicinity of the inferred contact is indistinguishable. It is noted that in FC colour ratio maps (e.g., F8 $(0.44 \mu \mathrm{m}) / \mathrm{F} 3(0.75 \mu \mathrm{m}))$ a more northerly extent of Yalode ejecta material is implied (cp. Fig. 2 in Schmedemann et al., 2016), although colour variegation of Ceres' dark surface is very small. Yalode ejecta continues from Yalode's rim to the south in the Ac14 Yalode Quadrangle across the quadrangle boundary with similar 
morphology and texture to that seen in the SW of the Rongo quadrangle (Crown et al., 2017, this issue).

Interpretation: Emplacement of thick Yalode-sourced ejecta material in the SW portion of the quadrangle. Dissection of ejecta material is caused by (1) Yalode-induced, post-emplacement secondary impacts forming furrows or closely spaced crater chains, which degrade over time to appear akin to trough-like features and/or (2) emplacement of water-ice rich material, which degraded through sublimation forming rugged terrain at proximal to medial reaches. The enclosed depression could represent a former large impact structure with the small tholus being the tip of a central peak.

\subsubsection{Impact crater materials (c-cb-cfh-ta-cr-crdeg)}

Crater materials comprise degraded crater rim material (crdeg) and crater floor (crater floor material hummocky-cfh), talus (i.e., crater wall material-ta), and ejecta materials. The latter are divided into crater material (undivided $-c$ ), bright crater material $(c b)$ and crater ray material (cr) (Fig. 6).

Bright crater material $(c b)$ consists of high-albedo material (reflectance up to 0.06 at $0.55 \mu \mathrm{m}$ ) intermixed with "average" surface material and occurs within ejecta, crater floor, rim and talus materials. The areal proportion of bright material is minor relative to the extent of remaining crater material unit. The occurrence of bright material with a typical white to bluish appearance is easily detected in false colour RGB or colour ratio maps. Bright crater material is associated with fresh (i.e., young) to slightly degraded craters. The exception is the unnamed crater within Begbalel Crater, where bright material with reflectance values up to 0.06 at $0.55 \mu \mathrm{m}$ is re-exposed by small impact craters.

Hummocky crater floor materials (cfh) are present in transitional complex and complex craters, which are typically larger than $10 \mathrm{~km}$ in diameter (Hiesinger et al., 2016). In addition to the hummocky texture a subdued ridged morphology is observed. On the floor of young craters large boulders $>100 \mathrm{~m}$ in diameter are present.

Talus material $(t a)$ refers to unconsolidated crater wall materials forming slopes of $27^{\circ}-50^{\circ}$ (typically $30^{\circ}-40^{\circ}$ ). Only in rare occurrences isolated, consolidated exposures are present near the rim crest.

Rayed crater material $(c r)$ is associated with ejecta material sourced from Haulani Crater ( $34 \mathrm{~km}$ in diameter) and varies in thickness, partially or fully covering pre-existing topography (Figs. 4 and 6). Single, isolated patches of rayed material are found up to $455 \mathrm{~km}$ from source (Fig. 8e and f). At medial to distal reaches, individual rays exhibit decreasing thickness from the centre to the margins and with increasing distance from the source (i.e., ejecta ray thickness decreases laterally and longitudinally). The texture of rayed material is smooth with a typical diffuse appearance. If steep slopes are prevalent (i.e., preexisting crater walls), thin lobate flows developed following ejecta emplacement. Note that many prevailing small bright-to-bluish spots within cratered terrain material may represent exposure of Haulani-sourced secondary impacts.

In three instances (near Ahuna Mons and Rongo Crater), mapped crater ejecta material $(c)$ is neither bright nor rayed. The deposits appear relatively smooth and boulders are present near the rim of fresh craters. Occasionally subdued radial striations are observed. The degraded crater rim material (crdeg) is similar in texture to the cratered terrain. The arcuate shape is only discernible in the DTM, although in places, minor variations in lighting and shading of the slightly steeper inner rim hint at a subdued positive landform. The degraded crater rim is also mapped (and better recognisable) in the adjacent Yalode quadrangle (Crown et al., 2017, this issue).

\subsection{Crater-based model ages}

Impact craters-the dominant geological features in the quadrangle-can be utilised by analysing their size frequency distribution to estimate absolute model ages of planetary geological surface units (e.g., Arvidson et al., 1979; Platz et al., 2013; Hiesinger et al., 2016). The crater density of a given area can be visualised by using kernel density maps (see method section). Fig. 5a shows a kernel density map for the Ac-10 Rongo Quadrangle, in which regions of lower crater density (deep blue) alternate with areas of higher density (brown). Comparing this map to the geological map (Fig. 6) it is apparent that crater deficiency in some areas is caused by the formation and emplacement of crater materials. The SW portion of the quadrangle is affected by the emplacement of Yalode ejecta, while the mid-northern and eastern regions are influenced by the formation of craters Begbalel, Rongo, Hatipowa, and Haulani with subsequent destruction and/or burial of pre-existing smaller craters.

Recognising and mapping the extent of Yalode ejecta material $(Y e)$ is challenging, especially in its distal portions (cf. Crown et al., 2017, this issue). The contact with cratered terrain is difficult to identify precisely. That Yalode ejecta was deposited within the Ac10 Rongo Quadrangle is absolutely certain, given that the rim of this $260-\mathrm{km}$ diameter basin is located only $35 \mathrm{~km}$ south of the quadrangle border. Because no direct contact relations of ejecta materials and the cratered terrain can be observed for any older and degraded large impact structure, crater size-frequency distributions were utilised to inform geological mapping efforts and to explore the potential extent of Yalode ejecta material. Therefore, all craters larger than $1.7 \mathrm{~km}$ diameter across the quadrangle were mapped (Fig. 5). The reduced crater density at $12^{\circ} \mathrm{N} / 288^{\circ} \mathrm{E}$ (Fig. 5a), or approx. $320 \mathrm{~km}$ north of Yalode's rim and anything to the south and southeast from this point, may reflect a resurfacing event, i.e., the emplacement of Yalode ejecta. The mapped extent of Yalode ejecta material ( $\mathrm{Ye}$ ) extends from the basin rim to distances between $210 \mathrm{~km}$ to $295 \mathrm{~km}$ (Fig. 6). All craters larger than $800 \mathrm{~m}$ in diameter were mapped in $5^{\circ}-7^{\circ}$ wide swaths to verify this initial result and to also potentially date the Yalode impact and explore the effects of this resurfacing event on smaller impact craters. Swath locations are based on the global $5^{\circ}$ graticule and changes in crater density are observed (red circles in Fig. 5b). For the crater population of $\mathrm{D} \geq 1.7 \mathrm{~km}$ mapped on Yalode ejecta, a model age of $530 \pm 40$ Ma results. For the higher resolution count of unit Ye (portion of swath \#1), a model age of $580 \pm 40 \mathrm{Ma}$ is estimated (Annex 7). These model ages are in agreement with the formation age of Yalode ( $580 \pm 40 \mathrm{Ma}$ ) as reported in Crown et al. (2017, this issue) where the entire mapped Yalode ejecta extent across the Occator, Rongo, Urvara, Yalode, and Zadeni quadrangles was used as counting area.

In order to explore potential crater density variations of the cratered terrain within the Ac-10 Rongo Quadrangle, all craters with $\mathrm{D} \geq 1.7 \mathrm{~km}$ and for selected swaths all craters with $\mathrm{D} \geq 0.8 \mathrm{~km}$ were mapped (see above; Fig. 5). For the entire unit crt $(D \geq 1.7 \mathrm{~km})$, a best-fit model age of $1.8 \pm 0.1 \mathrm{Ga}$ is determined (Fig. 10). A similar model age $(1.8 \pm 0.2 \mathrm{Ga})$ for unit crt is derived from the combined area of swaths $1-5(\mathrm{D} \geq 0.8 \mathrm{~km})$. Note for swaths 3 and 5 , best-fit model ages are $1.8 \pm 0.2 \mathrm{Ga}$ and $1.7 \pm 0.2 \mathrm{Ga}$, respectively (Annex 7). The result from swath 4 (approx. $1.9 \pm 0.4 \mathrm{Ga}$ ) does not match the production function of Hiesinger et al. (2016) (Annex 7). It is noted that the CSFD of swath 5 records a resurfacing event at $520 \pm 20 \mathrm{Ma}$ (Fig. 10). This event likely reflects the formation of the Yalode basin, and in turn, indicates a more northerly extent of its ejecta material beyond the inferred extent of unit Ye (Fig. 6). Liberalia Mons exhibits a surface texture indistinct from the cratered terrain-so does its CSFD $(1.7 \pm 0.2 \mathrm{Ga})$ (Annex 7). 
The crater size-frequency distribution of the unnamed tholus within Begbalel Crater remains elusive (Annex 7). However, a minimum formation age of $1.9(1 \sigma:+0.5 \mathrm{Ga},-0.4 \mathrm{Ga})$ for the tholus is estimated by using the impact crater population superimposed on Begbalel Crater (Annex 7).

\section{Geological evolution}

Detailed geological mapping of surface textures and landforms prevalent within the Ac-10 Rongo Quadrangle revealed nine geological units of which one unit-tholus material (th)-is distinct from otherwise dominant impact crater materials (Fig. 6, Fig. 11). The oldest unit is a degraded rim (crdeg) of a c. $200 \mathrm{~km}$ diameter impact basin. The most widespread unit within the quadrangle is the cratered terrain $(\mathrm{crt}$ ) which formed at about $1.8 \mathrm{Ga}$. The unnamed tholus within Begbalel Crater is tentatively interpreted to be a volcanic edifice. Its formation age is difficult to constrain but it postdates the formation of Begbalel Crater $(1.8 \pm 0.4 \mathrm{Ga})$. At approximately $580 \mathrm{Ma}$ a major impact event occurred on Ceres forming the $260 \mathrm{~km}$ diameter Yalode basin. A large portion of ejecta material was deposited with the Rongo quadrangle. The formation age of Yalode is given in Crown et al. (2017, this issue) at $580 \pm 40 \mathrm{Ma}$.

The cratered terrain is Ceres' most widespread surface unit (Buczkowski et al., 2016; Mest et al., 2017), and its strong variation in crater density across the globe (Hiesinger et al., 2016) suggests a rather heterogeneous geological history. Lunar-derived model ages for the cratered terrain determined within different quadrangles vary considerably within the range 1.4-3.4 Ga (Pasckert et al., 2017, this issue; Schulzeck et al., 2017, this issue; Scully et al., 2017, this issue; Williams et al., 2017, this issue). The crater size-frequency distribution mapped on the cratered terrain within the Rongo quadrangle, however, appears homogeneous. The observed large variation in model ages for the cratered terrain could be related to the formation of very large impact basins, which may only be identified in gravity and filtered topography data (Marchi et al., 2016).

Ahuna Mons is a cryovolcanic edifice that formed through exogenous and endogenous dome growth, i.e., through extrusion and inflation due to intrusion of cryomagma under the dome's crust (Ruesch et al., 2016). Placing time constraints on the evolution of Ahuna Mons proves difficult due to its enormous dimensions and the time needed to construct such an edifice and the low preservation potential of impact craters on steep slopes inhibiting reliable crater-based age estimates. Although the initial edifice-building phase could have started before the formation of the Yalode basin based on contact relations (i.e., SE portion of the edifice and the lack of smooth talus), most of the present-day edifice was emplaced at about $200 \mathrm{Ma}$ (Ruesch et al., 2016). The sharp contact between flank material and the surrounding terrain to the northwest, north, and northeast, however, may suggest a late-stage growth phase at $\ll 200 \mathrm{Ma}$.

More recently at $\sim 2.5 \mathrm{Ma}$, the $34 \mathrm{~km}$ diameter crater Haulani formed (Schmedemann et al., 2016); portions of its ejecta blanket and rays were emplaced within the Rongo quadrangle. Haulani Crater rays serve as upper stratigraphic marker horizon for some impact crater materials (Fig. 6).

Six smaller impact craters excavated bright sub-surface material mapped as bright crater material $(c b)$. Five of those craters exhibit relatively fresh to slightly degraded crater morphologies implying rather recent formation ages. The smaller of the two craters atop Liberalia Mons (Fig. 8c and d) exhibits fluidised ejecta flows similar to those observed at Haulani Crater (Krohn et al., 2016). One crater located within Begbalel Crater is moderately to heavily degraded. Originally its ejecta contained bright material at the surface which was either blanketed by foreign ejecta or matured optically (i.e., darkened) over time (cf. Schmedemann et al., 2016). Buried bright material has then been re-exposed by subsequent primary and secondary impact events.

\section{Acknowledgements}

This research has made use of the USGS Integrated Software for Imagers and Spectrometers (ISIS). We thank the Dawn spacecraft and instrument teams for their excellent work in acquiring the data. Two anonymous reviewers are acknowledged for their suggestions, which helped improving the presentation of this study. The Framing Camera project is financially supported by the Max Planck Society and the German Space Agency.

\section{Supplementary materials}

Supplementary material associated with this article can be found, in the online version, at doi:10.1016/j.icarus.2017.08.001.

\section{References}

Arvidson, R.E., Boyce, J., Chapman, C., Cintala, M., Fulchignoni, M., Moore, H., Neukum, G., Schultz, P., Soderblom, L., Strom, R., Woronow, A., Young, R., 1979. Standard techniques for presentation and analysis of crater size-frequency data. Icarus 37, 467-474.

Becker, K.J., Archinal, B.A., Hare, T.M., Kirk, R.L., Howington-Kraus, E., Robinson, M., Rosiek, M.R., 2015. Criteria for automated identification of stereo image pairs. 46th Lunar and Planetary Science Conference, abstract \#2703.

Buczkowski, D.L., Schmidt, B., Williams, D.A., Mest, S.C., Scully, J.E.C., Ermakov, A.I., Preusker, F., Schenk, P., Otto, K.A., Hiesinger, H., O'Brien, D., Marchi, S., Sizemore, H., Hughson, K., Chilton, H., Bland, M., Byrne, S., Schorghofer, N., Platz, T., Jaumann, R., Roatsch, T., Sykes, M.V., Nathues, A., De Sanctis, M.C., Raymond, C.A., Russell, C.T., 2016. The geomorphology of Ceres. Science 353, aaf4332.

Buczkowski, D.L. Williams, D.A. Scully, J.E.C. Mest, S.C., Crown, D.A. Schenk, P.M., Jaumann, R., Roatsch, T., Preusker, F., Nathues, A., Hoffmann, M., Schaefer, M., Marchi, S., De Sanctis, M.C., Raymond, C.A., Russell, C.T. The geology of the Occator quadrangle of dwarf planet Ceres: floor-fractured craters and other geomorphic evidence of cryomagmatism. Icarus, Special Issue "The Geologic Mapping of Ceres" (2017, this issue).

Crown, D.A., Sizemore, H.G., Yingst, R.A., Mest, S.C., Platz, T., Berman, D.C., Schmedemann, N., Buczkowski, D.L., Williams, D.A., Roatsch, T., Preusker, F., Raymond, C.A., Russell, C.T. Geologic mapping of the Urvara and Yalode quadrangles of Ceres. Icarus, Special Issue "The Geologic Mapping of Ceres" (2017, this issue).

De Sanctis, M.C., Coradini, A., Ammannito, E., Filacchione, G., Capria, M.T., Fonte, S. Magni, G., Barbis, A., Bini, A., Dami, M., Ficai-Veltroni, I., Preti, G., 2011. The VIR spectrometer. Sp. Sci. Rev. 163, 329-369.

FGDC, 2006. Digital Cartographic Standard for Geologic Map Symbolization. U.S Federal Geographic Data Committee FGDC-STD-013-2006.

Hayne, P.O., Aharonson, O., 2015. Thermal stability of ice on Ceres with rough topography. J. Geophys. Res. 120, 1567-1584.

Hiesinger, H., Marchi, S., Schmedemann, N., Schenk, P., Pasckert, J.H., Neesemann, A., O’Brien, D.P., Kneissl, T., Ermakov, A.I., Fu, R.R., Bland, M.T., Nathues, A Platz, T., Williams, D.A., Jaumann, R., Castillo-Rogez, J.C., Ruesch, O., Schmidt, B., Park, R.S., Preusker, F., Buczkowski, D.L., Russell, C.T., Raymond, C.A., 2016. Cratering on Ceres: implications for its crust and evolution. Science 353, aaf4759.

Hughson, K.H.G., Russell, C.T., Williams, D.A., Buczkowski, D.L., Mest, S.C., Pasckert, J.H., Scully, J.E.C., Combe, J.-Ph., Platz, T., Ruesch, O., Preusker, F., Jaumann, R., Nass, A., Roatsch, T., Nathues, A., Schaefer, M., Schmidt, B.E., Chilton, H.T., Ermakov, A., and McFadden, L.A. The Ac-H-5 (Fejokoo) quadrangle of Ceres: geologic map and geomorphological evidence for ground ice mediated surface processes. Icarus, Special Issue "The Geologic Mapping of Ceres" (2017, this issue).

Huppert, H.E., Shepherd, J.B., Sigurdsson, H., Sparks, R.S.J., 1982. On lava dome growth, with application to the 1979 lava extrusion of the Soufrière of St. Vincent. J. Volcanol. Geotherm. Res. 14, 199-222.

Kneissl, T., van Gasselt, S., Neukum, G., 2011. Map-projection-independent crater size-frequency determination in GIS environments-New software tool for $\mathrm{Ar}$ cGIS. Planet. Sp. Sci. 59, 1243-1254.

Krohn, K., Jaumann, R., Stephan, K., Otto, K.A., Schmedemann, N., Wagner, R.J., Matz, K.-D., Tosi, F., Zambon, F., von der Gathen, I., Schulzeck, F., Schröder, S.E. Buczkowski, D.L., Hiesinger, H., McSween, H.Y., Pieters, C.M., Preusker, F., Roatsch, T., Raymond, C.A., Russell, C.T., Williams, D.A., 2016. Cryogenic flow features on Ceres: implications for crater-related cryovolcanism. Geophys. Res. Lett. 43 11,994-12,003.

Krohn, K., Jaumann, R., Otto, K.A., Schulzeck, F., Neesemann, A., Nass, A., Stephan, K. Tosi, F., Wagner, R.J., Zambon, F., von der Gathen, I., Williams, D.A., Buczkowski, D.L., De Sanctis, M.C., Kersten, E., Matz, K.-D., Mest, S.C., Pieters, C.M., Preusker, F., Roatsch, T., Scully, J.E.C., Russell, C.T., Raymond, C.A. The unique geomorphology and structural geology of the Haulani crater of dwarf planet Ceres as revealed by geological mapping of equatorial quadrangle Ac-6 Haulani. Icarus, Special Issue "The Geologic Mapping of Ceres" (2017, this issue). 
Marchi, S., Ermakov, A.I., Raymond, C.A., Fu, R.R., O’Brien, D.P., Bland, M.T., Ammannito, E., De Sanctis, M.C., Bowling, T., Schenk, P., Scully, J.E.C., Buczkowski, D.L., Williams, D.A., Hiesinger, H., Russell, C.T., 2016. The missing large impact craters on Ceres. Nat. Commun. 7, 12,257.

Mest, S.C., Crown, D.A., Yingst, R.A., Berman, D.C., Williams, D.A., Buczkowski, D.L., Scully, J.E.C., Platz, T., Jaumann, J., Roatsch, T., Preusker, F., Nathues, A., Hiesinger, H., Pasckert, J.H., Raymond, C.A., Russell, C.T., 2017. The global geologic map of Ceres based on Dawn HAMO observations. 48th Lunar and Planetary Science Conference, abstract \#2512.

Michael, G.G., Neukum, G., 2010. Planetary surface dating from crater size-frequency distribution measurements: partial resurfacing events and statistical age uncertainty. Earth Planet. Sci. Lett. 294, 223-229.

Michael, G.G., Kneissl, T., Neesemann, A., 2016. Planetary surface dating from crater size-frequency distribution measurements: Poisson timing analysis. Icarus 277, 279-285.

Michael, G.G., Platz, T., Kneissl, T., Schmedemann, N., 2012. Planetary surface dating from crater size-frequency distribution measurements: Spatial randomness and clustering. Icarus 218, 169-177.

Nass, A., van Gasselt, S., Jaumann, R., Asche, H., 2011. Implementation of cartographic symbols for planetary mapping in geographic information systems. Planet. Space Sci. 59, 1255-1264.

Nass, A., Nelson, D., Williams, D., van Gasselt, S., Jaumann, R., Buczkowski, D.L., Scully, J.E.C., Mest, S.C., 2015. GIS-based template for geological mapping - Ceres use case. International Society for Photogrammetry and Remote Sensing (ISPRS), 24-25 September 2015, Berlin, Germany.

Nass, A., 2017. One GIS-based data structure for geological mapping using 15 map sheets-Dawn at Ceres. 48th Lunar and Planetary Science Conference, abstract 1892.

Nathues, A., Hoffmann, M., Schaefer, M., Le Corre, L., Reddy, V., Platz, T., Cloutis, E.A., Christensen, U., Kneissl, T., Li, J.-Y., Mengel, K., Schmedemann, N., Schaefer, T., Russell, C.T., Applin, D.M., Buczkowski, D.L., Izawa, M.R.M., Keller, H.U., O’Brien, D.P., Pieters, C.M., Raymond, C.A., Ripken, J., Schenk, P.M., Schmidt, B.E., Sierks, H., Sykes, M.V., Thangjam, G.S., Vincent, J.-B., 2015. Sublimation in bright spots on (1) Ceres. Nature 528, 237-240.

Nathues, A., Hoffmann, M., Platz, T., Thangjam, G.S., Cloutis, E.A., Reddy, V., Le Corre, L., Li, J.-Y., Mengel, K., Rivkin, A., Applin, D.M., Schaefer, M., Christensen, U., Sierks, H., Ripken, J., Schmidt, B.E., Hiesinger, H., Sykes, M.V., Sizemore, H.G., Preusker, F., Russell, C.T., 2016. FC colour images of dwarf planet Ceres reveal a complicated geological history. Planet. Space Sci. 134, 122-127.

Nathues, A., Platz, T., Hoffmann, M., Thangjam, G., Cloutis, E.A., Applin, D.M., Le Corre, L., Reddy, V., Mengel, K., Protopapa, S., Takir, D., Preusker, F., Schmidt, B.E., Russell, C.T., 2017. Oxo crater on (1) Ceres - geological history and the role of water ice. Astronom. J. 154, 84 (doi: https://doi.org/10.3847/1538-3881/aa7a04).

Pallister, J.S., Diefenbach, A.K., Burton, W.C., Muňoz, J., Griswold, J.P., Lara, L.E., Lowenstern, J.B., Valenzuela, C.E., 2013. The Chaitén rhyolite lava dome: Eruption sequence, lava dome volumes, rapid effusion rates and source of the rhyolite magma. Andean Geol. 40, 277-294.

Pasckert, J.H., Hiesinger, H., Ruesch, O., Williams, D.A., Kneissl, T., Mest, S.C., Buczkowski, D.L., Scully, J.E.C., Schmedemann, N., Jaumann, R., Roatsch, T., Preusker, F., Nass, A., Nathues, A., Hoffmann, M., Schäfer, M., De Sanctis, M.C., Raymond, C.A., Russell, C.T. Geologic mapping of the Ac-2 Coniraya Quadrangle of Ceres from NASA's Dawn mission: Implications for a heterogeneously composed crust. Icarus, Special Issue "The Geologic Mapping of Ceres" (2017, this issue).

Platz, T., Cronin, S.J., Procter, J.N., Neall, V.E., Foley, S.F., 2012. Non-explosive, domeforming eruptions at Mt. Taranaki, New Zealand. Geomorphology 136, 15-30.

Platz, T., Michael, G.G., Tanaka, K.L., Skinner Jr., J.A., Fortezzo, C.M., 2013. Crater-based dating of geological units on Mars: methods and application for the new global geological map. Icarus 225, 806-827.

Platz, T., Nathues, A., Crown, D.A., Mest, S.C., Williams, D.A., Hoffmann, M., Schaefer, M., Sizemore, H.G., Ruesch, O., Preusker, F., 2015a. Initial geological maps of the Ac-H-10 Rongo and Ac-H-15 Zadeni quadrangles of Ceres using Dawn spacecraft data. GSA Annual Meeting in Baltimore, Maryland, USA, 1-4 November 2015, abstract \#308-10.

Platz, T., Nathues, A., Crown, D., Mest, S.C., Williams, D., Hoffmann, M., Schaefer, M., Sizemore, H., Yingst, R.A., Ruesch, O., Buczkowski, D., Kneissl, T., Schmedemann, N., Hughson, K., Preusker, F., Russell, C.T., 2015b. Preliminary geological maps of the Ac-H-10 Rongo and Ac-H-15 Zadeni quadrangles: an integrated mapping study using Dawn spacecraft data. AGU, San Francisco, CA, December 2015.

Platz, T., Nathues, A., Ruesch, O., Sizemore, H.G., Schaefer, M., Hoffmann, M., Crown, D.A., Mest, S.C., Yingst, R.A., Williams, D.A., Kneissl, T., Schmedemann, N., Nass, A., Preusker, F., 2016a. Geological mapping of the Ac-H-10 Rongo quadran- gle of Ceres. The Annual Planetary Geologic Mappers Meeting, Flagstaff, 13-15 June 2016, \#7030.

Prettyman, T.H., Feldman, W.C., McSween, H.Y., Dingler, R.D., Enemark, D.C. Patrick, D.E., Storms, S.A., Hendricks, J.S., Morgenthaler, J.P., Pitman, K.M., Reedy, R.C., 2011. Dawn's gamma ray and neutron detector. Space Sci. Rev. 163, 371-459.

Preusker, F., Scholten, F., Matz, K.-D., Elgner, E., Jaumann, J., Roatsch, T., Joy, S.P., Polansky, C.A., Raymond, C.A., Russell, C.T., 2016. Dawn at Ceres - Shape model and rotational state. 47th Lunar and Planetary Science Conference, abstract \#1954.

Roatsch, T., Kersten, E., Matz, K.-D., Preusker, F., Scholten, F., Jaumann, R., Raymond, C.A., Russell, C.T., 2016a. High-resolution Ceres high altitude mapping orbit atlas derived from dawn framing camera images. Planet. Space Sci. 129, 103-107.

Roatsch, T., Kersten, E., Matz, K.-D., Preusker, F., Scholten, F., Jaumann, R., Raymond, C.A., Russell, C.T., 2016b. Ceres survey atlas derived from dawn framing camera images. Planet. Space Sci. 121, 115-120.

Ruesch, O., Platz, T., Schenk, P., McFadden, L.A., Castillo-Rogez, J.C., Quick, L.C., Byrne, S., Preusker, F., O’Brien, D.P., Schmedemann, N., Williams, D.A., Li, Y.-L., Bland, M.T., Hiesinger, H., Kneissl, T., Neesemann, A., Schaefer, M., Pasckert, J.H., Schmidt, B.E., Buczkowski, D.L., Sykes, M.V., Nathues, A., Roatsch, T., Hoffmann, M., Raymond, C.A., Russell, C.T., 2016. Cryovolcanism on Ceres. Science 353, aaf4286.

Schmedemann, N., Kneissl, T., Neesemann, A., Stephan, K., Jaumann, R., Krohn, K., Michael, G.G., Matz, K.-D., Otto, K.A., Raymond, C.A., Russell, C.T., 2016. Timing of optical maturation of recently exposed material on Ceres. Geophys. Res. Lett. 43 11,987-11,993.

Schröder, S.E., Maue, T., Gutiérrez-Marqués, P., Mottola, S., Aye, K.M., Sierks, H., Keller, H.U., Nathues, A., 2013. In-flight calibration of the Dawn Framing Camera. Icarus 226, 1304-1317.

Schulzeck, F., Krohn, K., van der Gathen, I., Schmedemann, N., Stephan, K., Jaumann, J., Williams, D.A., Buczkowski, D.L., Mest, S.C., Scully, J.E.C., Kersten, E., Matz, K.D., Nass, A., Preusker, F., Roatsch, T., Raymond, C.A., Russell, C.T. Geologic mapping of the Ac-11 sintana quadrangle: assessing diverse crater morphologies. Icarus, Special Issue "The Geologic Mapping of Ceres" (2017, this issue).

Scully, J.E.C., Buczkowski, D.L., Neesemann, A., Williams, D.A., Mest, S.C., Raymond, C.A., Hughson, K.H.G., Kneissl, T., Pasckert, J.H., Ruesch, O., Frigeri, A., Nass, A., Marchi, S., Combe, J.-P., Schmedemann, N., Schmidt, B.E., Chilton, H.T., Russell, C.T., Ermakv, A.I., Jaumann, R., Hoffmann, M., Nathues, A., Pieters, C.M., Preusker, F., Roatsch, T., Schaefer, M. The localized distribution of water ice on Ceres, as evidenced by geologic mapping of the northern-mid-latitude Ezinu quadrangle. Icarus, Special Issue "The Geologic Mapping of Ceres" (2017, this issue).

Sierks, H., Keller, H.U., Jaumann, R., Michalik, H., Behnke, T., Bubenhagen, F., Büttner, I., Carsenty, U., Christensen, U., Enge, R., Fiethe, B., Gutiérrez-

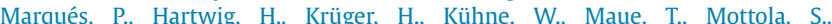
Nathues, A., Reiche, K.-U., Richards, M.L., Roatsch, T., Schröder, S.E., Szemerey, I., Tschentscher, M., 2011. The dawn framing camera. Space Sci. Rev. 163, 263-327.

Torson, J.M., Becker, K.J., 1997. ISIS - A software architecture for processing planetary images. XXVIII Lunar and Planetary Science Conference, abstract \#1219.

Williams, D.A., Buczkowski, D.L., Mest, S.C., Scully, J.E.C., Platz, T., Kneissl, T., 2017. Introduction: the geologic mapping of Ceres. Icarus, Special Issue "The Geologic Mapping of Ceres" $1-13$, this issue.

Williams, D.A., Kneissl, T., Neesemann, A., Mest, S.C., Palomba, E., Platz, T., Nathues, A., Longobardo, A., Scully, J.E.C., Ermakov, A., Jaumann, R., Buczkowski, D.L., Schäfer, M., Thangjam, G., Pieters, C.M., Roatsch, T., Preusker, F., Marchi, S. Schmedemann, N., Hiesinger, H., Frigeri, A., Raymond, C.A., Russell, C.T. The geology of the Kerwan quadrangle of dwarf planet Ceres: investigating Ceres' oldest impact basin. Icarus, Special Issue "The Geologic Mapping of Ceres" (2017, this issue).

Williams, D.A., Yingst, R.A., Garry, W.B., 2014. Introduction: the geologic mapping of Vesta. Icarus 244, 1-12.

Yingst, R.A., Mest, S.C., Berman, D.C., Garry, W.B., Williams, D.A., Buczkowski, D.L., Jaumann, R., Pieters, C.M., De Sanctis, M.C., Frigeri, A., Le Corre, L., Preusker, F., Raymond, C.A., Reddy, V., Russell, C.T., Roatsch, T., Schenk, P.M., 2014. Geologic mapping of Vesta. Planet. Space Sci. 103, 2-23.

Zambon, F., Raponi, A., Tosi, F., De Sanctis, M.C., McFadden, L.A., Carrozzo, F.G., Longobardo, A., Ciarniello, M., Krohn, K., Stephan, K., Palomba, E., Pieters, C.M., Ammannito, E., Russell, C.T., Raymond, C.A., 2017. Spectral analysis of Ahuna Mons frm Dawn mission's visible-infrared spectrometer. Geophys. Res. Lett. doi:10.1002/2016GL071303. 